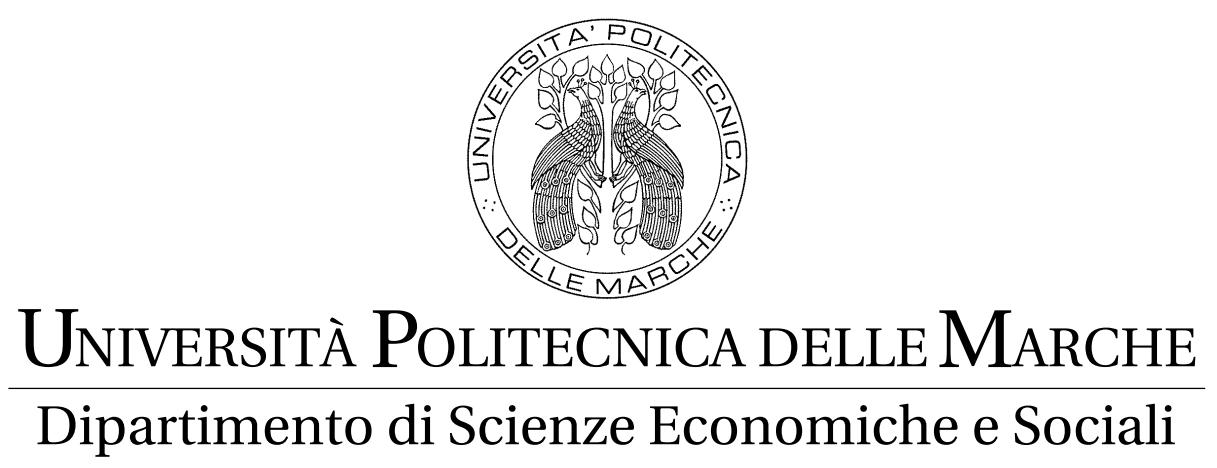

InCREASing Graduation AND CALLING FOR More Autonomy in Higher Education:

Is It A Good Thing? A Theoretical MODEL

Maria Cristina Recchioni

Stefano Staffolani

QUADERNI DI RICERCA n. 419

ISSN: 2279-9575

May 2016 
Comitato scientifico:

Marco Gallegati

Stefano Staffolani

Alessandro Sterlacchini

Alberto Zazzaro

Collana curata da:

Massimo Tamberi 


\begin{abstract}
This paper presents a theoretical model of enrollment decisions made by high school graduates, under the assumption that their choices are strongly influenced by the educational standard(s), roughly defined as what students are expected to have learned by the end of the course. Higher standards reduce the probability of graduation but increase the accumulation of human capital and future earnings. The policy maker decides whether standards are set equally for all universities (centralization) or autonomously by each university (decentralization). In the centralized setting, the model establishes relationships among the standards that maximize different objectives: graduation, enrollment, and human capital. Specifically, the standard that maximizes graduation is lower than the one that maximizes enrollment, which, in turn, is lower than the one that maximizes human capital. The decentralized setting may perform worse than the centralized one in terms of these three objectives if moving costs exist, while it always performs worse in terms of inter-generational mobility in education.
\end{abstract}

JEL Class.: J24, I21, I23

Keywords: Education, University, Standards, Human Capital, Inequality, Regulation of Educational System

Indirizzo: Maria Cristina Recchioni Department of Management, UNIVPM, Ancona - Italy. Corresponding Author, m.c.recchioni@univpm.it

Stefano StaffolaniDepartment of Economics and Social Sciences, UNIVPM, Ancona - Italy 



\title{
Increasing Graduation and Calling for More Autonomy in Higher Education: Is It a Good Thing? A Theoretical Model ${ }^{\dagger}$
}

\author{
Maria Cristina Recchioni Stefano Staffolani
}

\section{Introduction}

The Recommendations of the European Commission to Member States concerning education included in the "Lisbon Strategy" and in "Europe 2020 Targets" goes mainly in two directions:

- increasing the number of individuals completing third level education ${ }^{1}$;

- reinforcing decentralization 2 .

The goal of broader access and an improved success rate can be reached through many measures, i.e., by reducing tuition fees, facilitating access to grants, investing in university structures and teacher competences. In short, by facilitating access to students coming from less wealthy families ${ }^{3}$ and increasing the overall quality of the higher-education system. A huge body of literature shows that the labor market rewards workers not only according to their educational level, field, and grade, but also according to the quality of the university . The typical explanations for the wage premium differences

\footnotetext{
${ }^{\dagger}$ We wish to thank Riccardo Lucchetti and the participants to the XXX AIEL National Conference of Labour Economics held in Cagliari, September 18th, 2015, Italy.

1 "Reducing the rates of early school dropouts to below 10\%; at least $40 \%$ of 30-34-year-olds completing third level education" (http://ec.europa.eu/europe2020/ europe-2020-in-a-nutshell/targets/index_en.htm).

2 "European universities are calling for more autonomy in preparing their courses and managing their human resources and facilities... [] The Commission invites Member States to relax the regulatory framework to allow university leadership to undertake genuine change and pursue strategic priorities" (http://europa.eu/legislation_summaries/ education_training_youth/lifelong_learning/c11078_en.htm).

${ }^{3}$ As shown in Cappellari and Lucifora (2009), the Italian reform of tertiary education implementing the "Bologna Process", has increased the probability of enrollment mainly for individuals with good school performance and low parental background.

${ }^{4}$ Relationships between worker earnings and the quality of the college they attended
} 
among universities depend both on the selection of enrolled students (Hershbein (2013)), and on the actual quality of the higher-education institution. Nevertheless, differences among universities can also be due to the educational standards. Briefly, educational standards (also defined learning, or examination, or exit, or student-workload standards) describe what students are expected to have learned by the end of the course. They depend positively on the workload and difficulty of the exams and negatively on teaching effort (see Cantillon et al. (2011)).

Measuring these standards is a challenging problem, recently faced by the OECD study Assessment of Learning Outcomes in Higher Education (AH$E L O$ ). The goal of this study "is to provide data to governments, institutions, and students themselves on what students at the end of their first (bachelor level) degrees know and are able to do". Empirical results are expected for $202 \sqrt{5}$

As underlined by Bishop and Wossmann (2004), the institutions regulating educational standards that considerably influence student performance are "examination systems (Bishop (1997)), centralized decision-making versus school autonomy (Wobmann (2001))... and competition in the educational system (Hoxby $(2000))^{n ! 6}$.

In our view, the risk is that the goal of "increasing the number of individuals completing third level education" is actually mainly pursued by lowering the educational standards of the courses, as empirically described for Italy in Bratti et al. (2007): "Therefore, mass tertiary education, i.e., an increase in the number of graduates (and the fraction of the population with a university degree), can be achieved by a reduction in university standards".

Furthermore, "reinforcing decentralization" can also lead to lower educational standards. Some evidence on this comes from Brunello and Rocco (2008), who conclude that private schools can offer a lower educational standard because they attract students with a relatively high cost of effort, who would find the high standards of public schools excessively demanding. This case is supported for Italy, but not for the US.

have been empirically analyzed by Brewer et al. (1999), Black and Smith $(2006)$ for the US, Milla (2012) for Canada, Makiko and Tomohiko (2013) for Japan, Zhang et al. (2013) for China, Lindahl and Regnér (2005) for Sweden, Canaan and Mouganie (2014) for France, Chevalier and Conlon (2003) for the UK. All these papers control for college selectivity and some of them take into account individual unobserved heterogeneity among enrolled students.

${ }^{5}$ See: http://www.oecd.org/edu/skills-beyond-school/ahelo-main-study.htm.

${ }^{6}$ Educational standards are linked to literature on the "grading standard". For instance, Bagues et al. (2008) argue that the ratio between the number of exams that students passed and the number of exams that students should have taken "might capture both the students true quality and the easiness (or grading standards) of a given institution". 
In light of the previous discussion, this paper analyzes the relationship between educational standards, enrollment, graduation, and human capital accumulation both in centralized and decentralized higher-education settings, on the basis that standards are probably among the main determinants of human capital accumulation and earnings on the labor market.

The economic literature on educational standards frequently considers the policy maker's effectiveness in choosing the level of the standard. The seminal paper by Costrell (1994) theoretically analyzes the choices of a policy maker who sets the standard in order to maximize his social welfare function, knowing that students choose whether or not to meet the standards and that standards influence student incentives to make an effort. He concludes that an egalitarian policy maker set lower standards than the ones preferred by the median voter. Schwager (2013) deepen the previous analyzes by considering the direct democratic choice of the examination standard. The author shows that the median preferred standard is inefficiently low if the marginal cost of achieving higher performance reacts more sensitively to ability for high than for low abilities, and if the right tail of the ability distribution is longer than the left tail. Paola and Scoppa (2007) analyze how a "badly functioning labor market", where effective skills are scarcely rewarded, affects the behavior of the policy maker who maximizes a social welfare function. In the case standards are defined taking into account the effective productivity of skills, they will be set at a high level in order to encourage individuals' learning effort. Instead, if standards are set considering exclusively the return to the school, they will be set at a low level. The case of governments that, aiming to increase the number of individuals completing third-level education, set funding rules for universities based on the number of graduates is analyzed in Cantillon et al. (2011). They conclude that the policy maker's desire to induce universities to raise their teaching effort to a given educational standard can only be fulfilled if there is positive interaction between student ability, student effort, and teacher effort.

The link between educational standards and inequality is analyzed in Betts (1998). Featuring workers with heterogeneous abilities, the results show that higher educational standards increase the earnings of both the most and least able workers. Thus an egalitarian social planner may set higher standards than an income-maximizing social planner. The results mitigate the concern that higher standards are necessarily inegalitarian. Another paper Vauteren and Escriche (2006) shows that an increase in educational standards would help poor individuals with high ability if it is combined with other non-monetary measures.

The economic literature has also compared the outcomes of a centralized versus decentralized educational standards. Conditions under which central- 
ized educational standards raise welfare are extensively analyzed in Costrell (1997), and it is concluded that high degrees of egalitarianism, cross-district heterogeneity, and high rates of geographical mobility of graduates favor centralization because in such a case the benefit of high standards in any district are not fully appropriated by the graduates who meet the standard. Himmler and Schwager (2013) show that a school whose students are disadvantaged on the labor market applies less demanding standards because such students have fewer incentives to graduate.

In this paper, educational standards are viewed as the determinant of graduation probability and the skills acquired during study in a setting where students are differentiated according to their ability, as in Cantillon et al. (2011) 7

The standard can be set either by the policy maker at a given homogeneous level (centralization) or freely chosen by each university (decentralization). In the decentralized setting, if the family can bear moving costs, students self-select universities that best match their talent. The observed differences in the average graduate wage among universities depends therefore on self-selection and human capital accumulation during university: graduate students in high-standard universities offer a better signal and a higher human capital.

With respect to the previous literature we explicitly consider enrollment as a risky choice following Cantillon et al. (2011). Actually, standards act as "prices" of the risky investment in human capital: a higher standard implies a higher risk of dropping out (investment failure) and a higher wage (investment return)8. Furthermore, instead of considering the social welfare function alone, we consider the policy maker to have different objectives, namely enrollment, graduation, and human capital accumulation. We take into account moving costs, which must be faced only in the decentralized

\footnotetext{
${ }^{7}$ Students' ability, their effort during studies, teaching effort, and a stochastic error all define the student's level of "educational production" in the paper by Cantillon et al. 2001. If this level is higher than a given threshold, i.e., the educational standard, the student graduates. With respect to Cantillon et al. (2011), we do not consider the teaching effort, we explicitly define the graduation probability function (see Proposition 1), and we relegate the analysis of student effort in Appendix 4 because we reason on a reduced form of the model. Furthermore, we assume that, other than by the educational standard, student's future earnings are also affected by her/his talent. Finally, the goal of Cantillon et al. 2011 is to analyze different output parameters in the funding rule of university whereas here we are interested in comparing different objectives of the policy maker and different structures of the higher educational system.

${ }^{8}$ The model can apply to every choice where one among different costly investments can be made and the chosen investment increases lifelong utility with a success probability that depends positively on individual talent and negatively on the return of the investment.
} 
system.

We show that, for each individual, there exists a preferred standard that depends positively on his/her talent and that the enrollment decision is optimal only when the standard to which the individual can enroll is not outside a range around the preferred one, whose extent depends positively on the family willingness to finance higher education.

At the aggregate level, in the centralized case, the model shows that the level of standard that maximizes human capital accumulation is higher than the one that maximizes the enrollment or graduation rate9. Furthermore, we find that the standard that maximizes enrollment is negatively correlated with average family income.

The decentralized system clearly performs better than the centralized one in term of human capital accumulation, but only if the choice of university to enroll in can be made, i.e., only if the moving decision is financed for all students. If this is not the case and the share of students that cannot afford moving costs is sufficiently high, the number of graduates and human capital accumulation can be higher in a centralized system whose standard is efficiently chosen. Given that moving toward the preferred university is more likely for students from richer families - as also shown for Italy in Appendix $\mathrm{A}-\mathrm{a}$ decentralized system would reduce inter-generational mobility in education 10

The outline of the paper is as follows. Section 2 presents the individual optimal choices. Section 3 illustrates the aggregate behavior in the centralized and decentralized settings. Section 4 draws some conclusions. Appendix A contains empirical estimations of some the hypotheses and results of the model for Italy. Appendix B endogenizes the choice of effort during studies made by enrolled students. Appendix $\mathrm{C}$ contains the proofs of the propositions presented in the text.

\footnotetext{
${ }^{9}$ The graduation rate is the ratio between the number of graduates and the whole population of secondary school dropouts, the graduation probability is the ratio between the number of graduates and enrolled students.

${ }^{10}$ Actually, richer students seem not to be influenced in their choices by the distance of the university. From Denzler and Wolter (2011): "The results also show that distance does not influence study choices among students from the highest socioeconomic group, a finding that further indicates that distance to university is an expression of differences in the cost of a university education."
} 


\section{The Model}

We consider a cohort of students, each endowed with a given talent $\theta$ which is a real random variable with distribution function

$$
F(\theta)=\int_{0}^{\theta} \phi\left(\theta^{\prime}\right) d \theta^{\prime} \quad \theta \in(-\infty,+\infty)
$$

where $\phi(\theta)=0, \theta \in(-\infty, 0)$ and $\phi(\theta)=0, \theta \in(\bar{\theta},+\infty)$. Once a secondary school cycle has been completed, students should choose whether and where to enroll at university ${ }^{11}$. We assume that their choice depends on the educational standards $(x>0)$ offered by the academic institutions that influence both the expected probability of graduation and the accumulation of human capital during studies ${ }^{12}$

Assumption 1 The probability of graduation $0<p(x, \theta)<1$ is an increasing function of talent and a decreasing function of the standard. It complies with the following:

$$
\begin{gathered}
p_{x}^{\prime}(x, \theta)<0, \quad p_{\theta}^{\prime}(x, \theta)>0 ; \quad p_{x \theta}^{\prime \prime}(x, \theta)>0, \quad p_{x x}^{\prime \prime}(x, \theta)>0 ; \\
\lim _{x \rightarrow 0} p(x, \theta)=1 \quad \lim _{x \rightarrow \infty} p(x, \theta)=0 \quad \lim _{\theta \rightarrow 0} p(x, \theta)=0 ; \quad \lim _{x \rightarrow \infty} \varepsilon_{p x} \leq-1 ;
\end{gathered}
$$

where $\varepsilon$ denotes elasticities, and

$$
p(t x, t \theta)=p(x, \theta), \forall t>0,
$$

that is, $p(x, \theta)$ is homogenous of degree zero in $(x, \theta){ }^{13}$.

The wage rate of undergraduates (both non-enrolled and dropped-out students) is linearly dependent 14 on their talent, $\omega(0, \theta)$, such that $\frac{\omega(0, \theta)}{\theta}=1$. The wage rate of graduates in the university offering the standard $x$ is given by $\omega(x, \theta)$.

\footnotetext{
${ }^{11}$ The relationship between the ex-ante decision to start university and university outcomes is theoretically analyzed in the seminal paper by Altonji (1993), who consider that the former decision is made under uncertainty. Oppedisano (2009) present a model of educational choices with uncertainty in countries with open admission policies.

${ }^{12}$ Both the probability of graduation and well-being during studies depend on effort. Appendix B shows that, given a specific utility function and computing the optimal effort of students, once the optimal effort is substituted into the expected utility function, we obtain the same results as displayed below.

${ }^{13}$ Zero degree homogeneity strongly simplifies the analytics of the model and seems to be a "reasonable" assumption. It implies: a) $\theta p_{\theta}^{\prime}=-x p_{x}^{\prime} \rightarrow \varepsilon_{p \theta}=-\varepsilon_{p x}$; b) $p_{\theta}^{\prime}+\theta p_{\theta \theta}^{\prime \prime}=$ $-x p_{x, \theta}^{\prime \prime}$; c) $p_{x}^{\prime}+x p_{x x}^{\prime \prime}=-\theta p_{\theta x}^{\prime \prime}$.

${ }^{14}$ Linearity does not affect the results, but strongly simplifies the analysis. Results would not change if $\omega(0, \theta)$ was a concave function of $\theta$.
} 
Assumption 2 The wage premium from graduation, $w(x, \theta)=\omega(x, \theta)-$ $\omega(0, \theta)$, is an increasing, constant-elasticity function of standard and talent, such that:

$$
\varepsilon_{w, \theta}=1, \quad \text { where } \quad 0<\beta<1
$$

and

$$
\lim _{x \rightarrow \infty} p(x, \theta) w(x, \theta)=0 .
$$

Assumptions 1 and 2 imply that a negative relationship between graduation probability and average expected wage exists for all enrolled students 15 .

The lifelong utility associated with the non-enrollment choice for riskneutral individuals is given by

$$
V^{N}(\theta)=\frac{\omega(0, \theta)}{r}
$$

where $r$ is the discount rate.

The lifelong utility associated with the enrollment choice depends on the expected probability of graduation (see Assumption 1) and on the wage premium from graduation (see Assumption 2). It also depends on income during studies (lasting one period), which must be negatively affected by exogenous enrollment costs (tuition fees, books, and possible mobility costs) and positively affected by the willingness of the family to finance the education. Because of the higher propensity of the family to finance more talented children and because of grants devoted to more talented enrolled students, we assume that talent influences income positively during studies, given by $z \theta$, where $z$ summarize all the components connected to the costs and financing education for a student whose talent is $\theta=1$.

Therefore, the expected inter-temporal utility associated with the enrollment choice $\left(V^{E}\right)$ is given by

$$
V^{E}(x, \theta)=z \theta+\frac{1}{r(1+r)}[p(x, \theta) \omega(x, \theta)+(1-p(x, \theta)) \omega(0, \theta)],
$$

where the first addend represents the utility during studies and the second is the ex-ante lifelong utility after studies, given by the discounted sum of

\footnotetext{
${ }^{15}$ Empirical evidence of this assumption is hardly available. The Italian higher-education setting, Bagues et al. (2008), however, provides some evidence that standard and earnings are positively correlated: "... the case of the Italian funds-allocation system, which rewards universities according to the number of exams passed by their students. We find that university departments that rank higher according to this indicator actually tend to be significantly worse in terms of their graduates' performance in the labor market."
} 
the wage rate of skilled and unskilled workers weighted by the probability of graduation.

The variation in expected utility coming from the enrollment decision is therefore $V^{E}(x, \theta)-V^{N}(\theta)$. By defining the loss of income while studying as the difference between unskilled income and capitalized income during studies times $r$,

$$
Z=r[1-(1+r) z]>0,
$$

for each secondary school dropout ${ }^{16}$ We introduce the uni-period expected premium for enrolling function, $V(x, \theta, Z)$,

$$
\begin{aligned}
V(x, \theta, Z) & =\left[V^{E}(x, \theta)-V^{N}(\theta)\right] r(1+r) \\
V(x, \theta, Z) & =p(x, \theta) w(x, \theta)-Z \theta .
\end{aligned}
$$

The first addend, $p(x, \theta) w(x, \theta)$ indicates the expected human capital accumulation during studies because it represents the expected increase in the wage rate due to graduation weighted by the graduation probability. The second addend is the loss of income while studying.

We now explain the natural range of variation for the standard $x$. The highest talent ever observed is $\bar{\theta}$, and from Assumption 1 (i.e., $\varepsilon_{w, \theta}=1$ ) and Eq. (4), we obtain

$$
V(x, \theta, Z)=\theta\left(p(x, \theta) w_{\theta}^{\prime}(x, \theta)-Z\right) \leq \theta\left(p(x, \bar{\theta}) \max _{\theta} w_{\theta}^{\prime}(x, \theta)-Z\right)=\theta v(x) .
$$

In order to obtain meaningful results and given that $v(0)=-Z<0$ and $\lim _{x \rightarrow+\infty} v(x)=-Z$, the model's parameters must be such that the maximum value of the function $v$ attained at a given standard $x_{M}$ is strictly positive, $v\left(x_{M}\right)>0$. Thus, it is easy to see that the function $v(x)$ has at least two roots $\underline{x}$ and $\bar{x}$ and $x \in[\underline{x}, \bar{x}]$ holds ${ }^{17}$. That is,

$$
\begin{aligned}
& v(\underline{x})=p(\underline{x}, \bar{\theta}) \max _{\theta} w_{\theta}^{\prime}(\underline{x}, \theta)-Z=0, \\
& v(\bar{x})=p(\bar{x}, \bar{\theta}) \max _{\theta} w_{\theta}^{\prime}(\bar{x}, \theta)-Z=0 .
\end{aligned}
$$

\footnotetext{
${ }^{16}$ If $Z<0$ holds, then the student is always better off enrolling. Actually, some families could finance the enrollment decision with an amount of money higher than the expected earnings of the student as an unskilled worker, so that $Z<0$, but we remove this possibility. It also depends positively on the preference for the present, measured by $r$ if $z<\frac{A}{1+2 r}$. Poorer families are therefore the ones that have difficulties financing their children's studies (low $z$ ) and a high preference for the present (high $r$ ).

17 Standards lower than $\underline{x}$ generate an expected income that does not cover the loss of income during studies, while standards higher than $\bar{x}$ give a probability of graduation that is too low to make the enrollment decision convenient, even for the most talented student.
} 
The following proposition highlights the main features from the analysis of the expected premium for enrolling function, $V$.

Proposition 1 We have:

(a) The premium for enrolling function, $V(x, \theta, Z)$, is a decreasing function of $Z$.

(b) For any given standard $x, \underline{x} \leq x \leq \bar{x}$ (see Eqs. (6)-(7)), there exists a level of the talent, called the talent of the marginal enrolled student, $\underline{\theta}(x, Z)$, such that enrolling is indifferent to not enrolling.

(c) The talent of the marginal enrolled student, $\underline{\theta}(x, Z)$ is an increasing function of $Z$, that is, $\frac{\partial \theta}{\partial Z}>0$ and, as a function of $x$, it attains a unique minimum at $x=x_{E}(Z)$. Therefore, the following inequalities hold:

$$
\frac{\partial \underline{\theta}}{\partial x}<0 \forall \underline{x} \leq x<x_{E}(Z) ; \quad \frac{\partial \underline{\theta}}{\partial x}>0 \forall \bar{x} \geq x>x_{E}(Z) .
$$

In the following we denote the minimum value of the function $\underline{\theta}(x, Z)$ with $\underline{\underline{\theta}}(Z)$ (i.e., $\left.\underline{\underline{\theta}}(Z) \equiv \underline{\theta}\left(x_{E}(Z), Z\right)\right), Z>0$.

(d) The functions $x_{E}(Z)$ and $\underline{\theta}(Z), Z>0$, are positive constant-elasticity functions whose elasticity is $\frac{1}{\beta}$.

- See Appendix C, Proof 1

Therefore, more talented and wealthier students are more likely to enroll for every level of the standard that admits positive enrollment. The marginal enrolled student at standard $x$, defined as the student whose talent is such that $\theta=\underline{\theta}(x, Z)$, has a lower talent if (s)he comes from a richer family.

Proposition 2 For any given talent $\theta$ there exists a standard $x^{*}(\theta)$ that maximizes the premium for enrolling function. This optimal standard has the following features:

(a) $x^{*}(\theta)$ satisfies the following equation $\varepsilon_{p s}\left(x^{*}(\theta), \theta\right)+\beta=0$ so that it does not depend on the loss of income during studies $Z$ and $x^{*}(\underline{\underline{\theta}}(Z))=x_{E}$.

(b) The optimal standard $x^{*}$ is an increasing linear function of the student's talent. We have $\frac{d x^{*}(\theta)}{d \theta}=\frac{x^{*}(\theta)}{\theta}$.

(c) If a student chooses his/her optimal standard, that is, $x=x^{*}(\theta)$, the graduation probability does not depend on talent, that is $\frac{d p}{d \theta}\left(x^{*}(\theta), \theta\right)=$ 0 . 
- See Appendix C, Proof 2

Therefore, each student would like to enroll in the university offering her/his optimal standard. In so doing, (s)he maximizes the human capital accumulated during studies. Students endowed with a higher talent would like to enroll in universities offering a higher standard because the higher risk of dropping out in such universities is overcompensated by the higher expected wage. By choosing the optimal standard, students self-sort into universities so that the probability of graduation does not depend on individual talent anymore ${ }^{18}$. Furthermore, the elasticity of the optimal standard to the talent is 1: $\varepsilon_{x^{*} \theta}=1$.

Figure 2 shows a graphical representation of the model. With talent on the $y$-axis and the standard on the $x$-axis, the iso-premium for enrolling function ${ }^{19}, \underline{\theta}(x)$ of the marginal enrolled student for a given $Z$, is plotted. It also plots the optimal standard function $x^{*}(\theta)$, in its inverse form. Many interesting insights can be gained:

1. A secondary school dropout whose talent is $\theta_{0}$ will enroll at whatever standard $x$ such that $\underline{x} \leq \underline{x}_{0} \leq x \leq \bar{x}_{0} \leq \bar{x}$, where $\underline{x}_{0}, \bar{x}_{0}$ are two consecutive smallest solutions of the equation $V\left(x, \theta_{0}\right)=0$. The optimal standard is $x^{*}\left(\theta_{0}\right)$ (see Proposition 2).

2. Given $\bar{\theta}$, the maximum talent, no secondary school dropout will enroll at standards lower than $\underline{x}$ or higher than $\bar{x}$; no one prefers a standard lower than $x_{E}(\theta)$ or higher than $x^{*}(\bar{\theta})$ (see Propositions 1 and 2 ).

3. If the standard is set at $x_{E}$, then the talent of the marginal enrolled student is minimized and the enrollment rate is maximized (see Proposition 1 ).

4. If the standard is set at the level $\bar{x}_{0}$, the enrolled students will be all the individuals whose talent is $\theta>\theta_{0}$ (the enrollment rate is shown as $E\left(\underline{x}_{0}\right)$ and is obviously dependent on the $\phi(\theta)$ distribution). Among enrolled students at standard $\underline{x}_{0}$, the standard is lower than the optimal one for those individuals distributed in the $E_{1}$ zone and higher than the optimal one for those distributed in the $E_{2}$ zone (see Proposition 2).

\footnotetext{
${ }^{18}$ Some evidence concerning Italy is provided in Appendix A.

${ }^{19}$ From now on, for the sake of simplicity we omit the $Z$-dependence of the analyzed quantities.
} 
Figure 1: Iso-premium for enrolling for the marginal enrolled student and optimal standard.

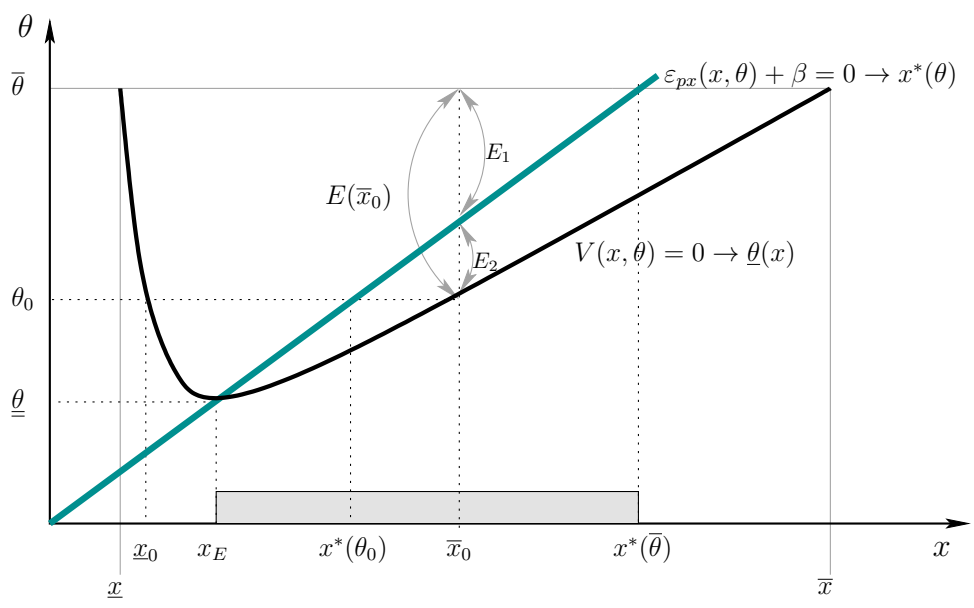

Remark: all the figures in the paper are from numerical simulations of the model based on the following functions and parameter values: $p(x, \theta)=\frac{\theta}{\theta+x} ; w(x, \theta)=1.4 \cdot \theta x^{\beta}$; uniform $\phi$ distribution, $\theta=\in[0,2] ; \beta=0.2 ; Z=0.58$.

5. All individuals whose talent is $\theta<\underline{\underline{\theta}}$ will never enroll at any standard (see Proposition 1).

6. The position of the curve $\underline{\theta}(x)$ depends on $Z$ and moves upward if $Z$ increases, $\left(\frac{\partial \theta(x)}{\partial Z}>0\right)$ (see Proposition 1). Individuals are more likely to enroll if their families (or the state) are more willing to finance their studies.

7. The threshold $\underline{\underline{\theta}}$ and standard $x_{E}$ both increase with $Z$ (see Proposition 1). Therefore, the share of individuals that will never enroll at any standard and the standard that minimizes the talent of the marginal enrolled student are higher if $Z$ is higher.

The previous analysis allows us to model the aggregate variables corresponding to enrollment, graduation, and human capital accumulation.

\section{The higher education institutional setting}

In this section, we consider an economic system characterized by a geographical distribution of universities such that: a) only one university is located 
in each district; b) the distribution of student talent in each district mirrors the one in the whole population.

We evaluate two different higher educational settings, the centralized standard case, Section 3.1 and the decentralized standard case, Section 3.2. The former case can be found in settings where the policy maker defines stringent criteria that each university must follow and, in its extreme form, implies course programs and the content of examinations strictly defined at the national level. The latter case defines a setting where each university freely chooses student curricula and the difficulty of the courses and exams.20.

Assumption 3 Both in centralization and decentralization, $x \in\left[x_{E}, x^{*}(\bar{\theta})\right]$. This interval corresponds to the standards preferred by the enrolled student ${ }^{21}$. The actual standard offered in each district is randomly drawn from a distribution $G(x)=\int_{-\infty}^{x} g\left(x^{\prime}\right) d x^{\prime}$, where $g(x)=0 \forall x<x_{E}$ or $x>x^{*}(\bar{\theta})$. Given that $x^{*}(\theta)$ is linear in $\theta$, the density $g(x)$ of the standard has the same functional form as the talent density, $\phi(\theta)$.

It is worth noting that in the centralized standard case each secondary school dropout chooses only whether to enroll at the "home" university or not, while in the decentralized setting each of them chooses whether to: a) not enroll; b) enroll at the university located in his/her district of residence (at home), accepting the random standard offered by the local university; c) move to the university offering his/her optimal standard, facing moving costs.

Assumption 4 Due to family financial constraints, a share, $q, 0 \leq q \leq 1$ of secondary school leavers cannot afford the moving costs. They are the stayers. Stayers and movers show the same distribution of talent, $\phi(\theta)$, because the moving decision is due only to financial constraints. Therefore, stayers are the secondary school leavers coming from "poor" families, movers are the ones coming from "rich families' 22 .

\footnotetext{
${ }^{20}$ In such a setting, each university could define its own goals and strategies. Further development of the model should analyze the optimal strategy of the universities in a context of territorial interdependence by using the tools of game theory.

${ }^{21}$ As shown in Figure 2 with the gray bar.

${ }^{22}$ Assumption 4 may be interpreted as follows: consider two different types of families, the "poor" and the "rich", characterized by a different propensity to finance education of their children, say $z_{P}$ and $z_{R}$, and assume that the moving decision is costly. We define with $z_{P S}, z_{P M}$ the utilities during studies of poor stayers and poor movers and with $z_{R S}, z_{R M}$ the ones of rich. By defining $\Xi(x, \theta)=\frac{p(x, \theta)[\omega(x, \theta)-\omega(0, \theta)]+\omega(0, \theta)}{r(1+r)}$, equation 2. written for stayers and movers, becomes:

$$
V_{i S}^{E}(x, \theta)=z_{i S} \theta+\Xi(x, \theta) \quad V_{i M}^{E}(\theta)=z_{i M} \theta+\Xi\left(x^{*}(\theta), \theta\right) \quad \text { for } i=P, R
$$
}


The previous assumption defines the stayers as a share $q$ of secondary school dropouts whose talent $\theta$ is such that $\theta \geq \underline{\theta}(x)$, where $x$ is randomly drawn from the distribution defined by $G$. The movers are defined as a share $1-q$ of secondary school dropouts whose talent $\theta$ is such that $\theta>\underline{\underline{\theta}}$. The former will enroll at the university offering the random standard $x$, and their human capital accumulation is $p(x, \theta) w(x, \theta)$. The latter will enroll at the university offering their optimal standard, and their human capital accumulation is $p\left(x^{*}(\theta), \theta\right) w\left(x^{*}(\theta), \theta\right)$. Obviously, $q$ strongly depends on the mobility cost:23.

In both settings, the aggregate variables of interest are the enrollment rate, $E$, the graduation rate, $G$, and the human capital accumulation $H$. By defining these three different objectives with $Y$, for $Y=E, G, H$, we are aware that $Y=Y(x)$ in the centralized system, where $x$ is the homogeneous standard set by the policy maker, and $Y=Y(q)$ in the decentralized system, where $q$ is the exogenous share of the population that cannot afford the moving costs.

\subsection{The centralized standard case}

We use $Y_{C}(x), x \in\left[x_{E}, x^{*}(\bar{\theta})\right]$ to denote the common representation of the policy maker's objective in the centralized case for the three possible targets (enrollment, graduation, human capital). Note that $Y_{C}(x)$ also depends on the loss of income while studying, $Z$, which we do not indicate for the sake of synthesis.

where $x$ is the random standard that each stayer find in her/his residence district while $x=x^{*}(\theta)$ is the optimal standard that each mover select by choosing the university where to enroll. Assumption 4 implies not only that mobility is more likely to be financed by rich families, so that $z_{P S} \gg z_{P M}$ and $z_{R S} \geq z_{R M}$, but takes this assumption to extremes, because it requires that the values of the $z_{i j}$, for $i=P, R$, and $j=S, M$, are such that the following holds:

$$
\forall \theta \geq \underline{\underline{\theta}}, x \geq x_{E}: \quad V_{P S}^{E}(x, \theta)>V_{P M}^{E}(\theta) \quad \text { and } \quad V_{R S}^{E}(x, \theta)<V_{R M}^{E}(\theta)
$$

so that poor are always better off by staying whereas rich are always better off by moving. Therefore, $q$ can also be interpreted as the share of poor in the population.

${ }^{23}$ In Italy, the decision to move is actually affected by the social class of the student's family, see Appendix A. 
The common representation of the targets is:

$$
\begin{array}{rlll}
Y_{C}(x)=\int_{\underline{\theta}(x)}^{\bar{\theta}} y(x, \theta) \phi(\theta) d \theta, & & \\
y(x, \theta)=1 & \text { if } Y=E & & \text { (Enrollment rate); } \\
y(x, \theta)=p(x, \theta) & \text { if } Y=G & \text { (Graduation rate); } \\
y(x, \theta)=p(x, \theta) w(x, \theta) & \text { if } Y=H & \text { (Human capital accumulation). }
\end{array}
$$

The functions $Y_{C}(x), Y=E, G, H$, are continuous functions on a compact set so they admit at least a global maximizer. We investigate the relationship (location in space) of these maximizers. We state:

Proposition 3 Let $x_{E}, x_{G}$ and $x_{H}$ be the standards that maximize the enrollment rate $E_{C}$, the graduation rate $G_{C}$, and the human capital accumulation $H_{C}$ respectively. Then $x_{E}$ is the unique maximizer of $E_{C}$. Assuming that $x_{G}$ and $x_{H}$ are the unique maximizers of $G_{C}$ and $H_{C}$, we have

$$
x_{G}<x_{E}<x_{H}<x^{*}(\bar{\theta}) .
$$

See Appendix C, Proof 3

¿From Proposition 3, it emerges that policies aimed at maximizing enrollment and graduation rates are suboptimal for human capital accumulation. In order to push the highest number of secondary school dropouts to enroll, the centralized standard, $x_{E}$, has to be set at a level that is lower than the one that maximizes the human capital accumulation. Figure 2 graphically illustrates the results of Proposition 3 .

\subsection{The heterogeneous standard case}

As previously mentioned, in this section we assume that enrolling in the preferred university generates moving costs. These costs cannot be faced by a share of the population, the stayers. Instead, moving decisions are completely financed by the movers' families.

The enrollment, graduation and human capital of movers are

$$
\begin{aligned}
Y_{M}=\int_{\underline{\underline{\theta}}}^{\bar{\theta}} y^{*}(\theta) \phi(\theta) d \theta, & \\
y^{*}(\theta)=1 & \text { if } Y=E ; \\
y^{*}(\theta)=p\left(x^{*}(\theta), \theta\right) & \text { if } Y=G ; \\
y^{*}(\theta)=p\left(x^{*}(\theta), \theta\right) w\left(x^{*}(\theta), \theta\right) & \text { if } Y=H,
\end{aligned}
$$


Figure 2: Enrollment (E), graduation (G), and human capital accumulation $(\mathrm{H})$ rates in the homogeneous standard case

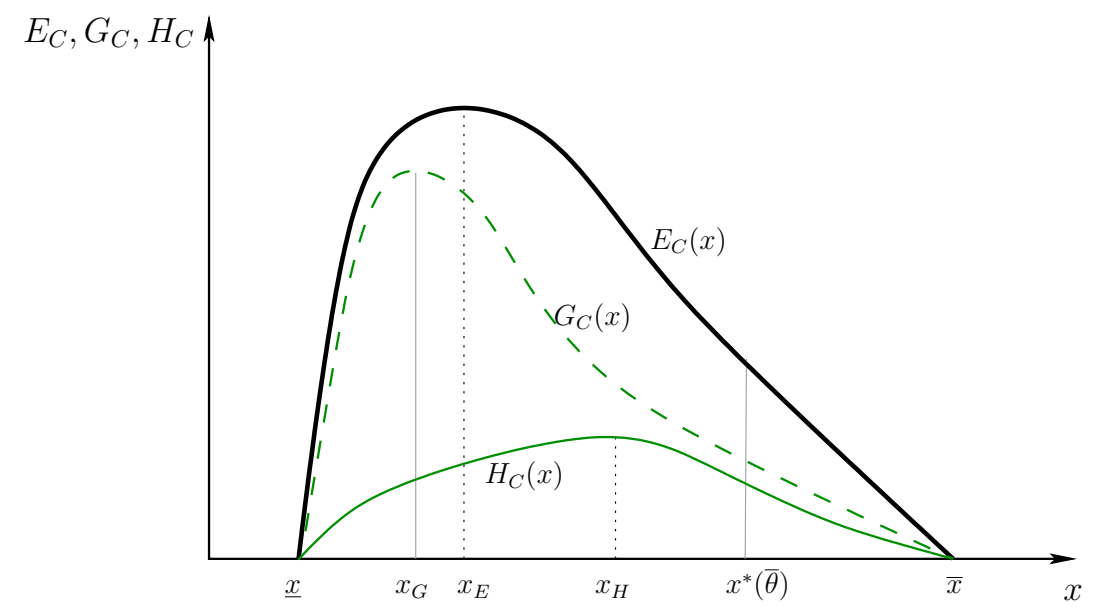

and for stayers,

$$
Y_{S}=\int_{x_{E}}^{x^{*}(\bar{\theta})} Y_{C}(x) f(x) d x \quad Y=E, G, H .
$$

Due to the fact that $\int_{x_{E}}^{x^{*}(\bar{\theta})} f(x) d x=1$ and $f(x) \geq 0, \underline{\theta}\left(x^{*}(\bar{\theta})\right)>\underline{\theta}(x)$, $x_{E} \leq x \leq x^{*}(\bar{\theta})$, we have

$$
\min _{x_{E} \leq x \leq x^{*}(\bar{\theta})} Y_{C}(x) \leq Y_{S} \leq \max _{x_{E} \leq x \leq x^{*}(\bar{\theta})} Y_{C}(x) \quad Y=E, G, H .
$$

This ensures that the enrollment, graduation, and human capital accumulation of stayers in the decentralized setting are always between the minimum and maximum attainable in the centralized setting and, more importantly, that the enrollment or graduation rate $Y_{C}(x)$ evaluated at the standard preferred by the most talented student is smaller than $Y_{S}$ since, roughly speaking, they are decreasing functions of the standard.

Given $q$, the share of stayers in the population of secondary school dropouts, the overall enrollment rate, graduation rate, and human capital accumulation in the decentralized setting are

$$
Y(q)=(1-q) Y_{M}+q Y_{S}, \quad Y=E, G, H
$$




\subsection{Comparing centralization and decentralization}

In this section we address the following question: given a standard level $x$, what are the values of the share $q$ that make the decentralized system preferable to the centralized one?

For $Y=E, G, H$, we introduce

$$
\Delta Y(x, q)=Y_{C}(x)-Y(q)=Y_{C}(x)-\left[(1-q) Y_{M}+q Y_{S}\right]
$$

Note that the centralized setting outperforms the decentralized one for the specific target defined by $Y$ when $\Delta Y(x, q)>0$. Therefore, our purpose is to identify the curve $q=q_{Y}^{*}(x)$ that separates the zone of the plane $(x, q)$ where the centralized system outperforms the decentralized one (i.e., $q>q_{Y}^{*}(x)$ ) and the zone where the decentralized system outperforms the centralized one (i.e., $\left.0 \leq q \leq q_{Y}^{*}(x)\right)$. This curve, $q=q_{Y}^{*}(x)$, is obtained by solving $\Delta Y(x, q)=0$ and observing that the inequality $\Delta Y(x, q) \geq 0$ can be rewritten as

$$
\begin{aligned}
& \Delta Y(x, q)=Y_{C}(x)-Y(q)=Y_{C}(x)-Y_{M}+q\left(Y_{M}-Y_{S}\right) \geq 0 \\
& \quad \longrightarrow \quad q\left(Y_{M}-Y_{S}\right) \geq Y_{M}-Y_{C}(x) .
\end{aligned}
$$

Eq. 15 shows that in order to derive the expression of the curve $q=q_{Y}^{*}(x)$, we have to analyze the sign of the quantities $Y_{M}-Y_{C}(x)$ and $Y_{M}-Y_{S}$. The following proposition addresses this point.

\section{Proposition 4 Movers}

For the movers, the decentralized setting is preferable to the centralized one when the objectives $E, H$ are pursued:

$$
Y_{M} \geq Y_{C}(x), \quad \forall x, x_{E} \leq x \leq x^{*}(\bar{\theta}), \quad Y=E, H .
$$

Moreover, the following inequality holds:

$$
Y_{M}>Y_{S}, \quad Y=E, H .
$$

See Appendix C, Proof 4 .

Proposition 4 simply states that the share of movers that enroll in the decentralized case cannot be lower than with centralization and that they cannot accumulate a lower human capital because, in fact, by choosing their preferred standard, they choose the standard that maximizes their human capita 24

\footnotetext{
${ }^{24}$ Proposition 4 does not refers to graduation because the graduation rate of movers can be higher or lower than the the stayers' rate or the one attainable in the central-
} 


\section{Proposition 5 Stayers}

For the stayers, the centralized setting is preferable to the decentralized one when $x$ is within the interval $\left[x_{1 Y}, x_{2 Y}\right]$, where $x_{1 Y}, x_{2 Y}$ are two consecutive solutions of the equation $Y_{C}(x)-Y_{S}=0$ in the interval $[\underline{x}, \bar{x}]$ (see Eqs. (6))(7)), $Y=E, G, H)$. Moreover:

a) when $Y=E$ we have $x_{1 E}<x_{E}<x_{2 E}<x^{*}(\bar{\theta})$; $E_{C}(x)>E_{S} \forall x \in$ $\left[x_{E}, x_{2 E}\right]$;

b) when $Y=G$, assuming that $G$ has a unique maximizer, then the inequality $x_{1 G}<x_{E}<x_{2 G}<x^{*}(\bar{\theta})$ holds; $G_{C}(x)>G_{S} \forall x \in\left[x_{E}, x_{2 G}\right]$;

c) when $Y=H$, assuming that $H$ has a unique maximizer, then the inequality $x_{1 H}<x_{H}<x_{2 H}$ holds; $H_{C}(x)>H_{S} \forall x \in\left[x_{1 H}, x_{2 H}\right]$

\section{See Appendix C, Proof 5}

Therefore, standards which make the centralized educational system preferable to the decentralized one for stayers always exist. In particular, the following inequalities hold: $E_{C}\left(x_{E}\right)>E_{S}, G_{C}\left(x_{E}\right)>G_{S}, H_{C}\left(x_{H}\right)>H_{S}$. In other words, if in the centralized case the standard is chosen at the value that maximizes one of the three objectives, then centralization outperforms decentralization for the stayer.

Theorem 1 Assume that the standard $x$ is such that $x_{E} \leq x \leq x^{*}(\bar{\theta})$ and $G_{M}>G_{S} 25$.

When $Y_{C}(x)>Y_{S}$, the quantity

$$
q_{Y}^{*}(x)=\frac{Y_{M}-Y_{C}(x)}{Y_{M}-Y_{S}} \quad \text { for } Y=E, H, G
$$

ized setting. In fact, by choosing the standard that maximizes their human capital accumulation, movers can face a lower probability of graduation than stayers or what is obtainable in centralization. Nevertheless, given that $G_{C}\left(x_{E}\right)>G_{S}, G_{C}\left(x_{E}\right)>G_{S}$ and $\frac{d G_{C}}{d x}<0 \forall x \in\left[x_{E}, x^{*}(\theta)\right]$ and given Eq. 12 , there are two values of the standard, say $x_{M}$ and a $x_{S}$, such that:

$$
G_{C}(x)>G_{M} \text { for } x<x_{M} \text { and } G_{C}(x)>G_{S} \text { for } x<x_{S} .
$$

Moreover, if $G_{M}>G_{S}$ then $x_{M}<x_{S}$, if $G_{M}<G_{S}$ then $x_{M}<x_{S}$.

Hereafter, we assume that $G_{M}>G_{S}$ since this assumption agrees with the finding for the enrollment rate and human capital accumulation. However, the main results of the paper still hold when $G_{M}<G_{S}$.

${ }^{25}$ If, instead, $G_{M}<G_{S}$, from Eq. 15 we see that centralization gives rise to a higher graduation rate if $q<\frac{G_{C}(x)-G_{M}}{G_{S}-G_{M}}$. For $x<x_{S}$, centralization prevails because $G_{C}(x)>$ $G_{S}>Y_{M} \rightarrow q>1$; for $x>x_{M}$ decentralization prevails because $G_{C}(x)<G_{M}<G_{S} \rightarrow$ $q<0$. For $x_{S}<x<x_{M}$, given $\frac{d G_{C}}{d x}<0$, there must exist a negative relationship between $q_{G}^{*}(x)$ and $x$ such that centralization prevails for $q<q_{G}^{*}(x)$. 
Figure 3: The functions $q_{E}^{*}(x), q^{*}\left(G(x)\right.$ and $q_{H}^{*}(x)$ as separators for the efficiency of centralization $(\Delta Y>0)$ or decentralization.

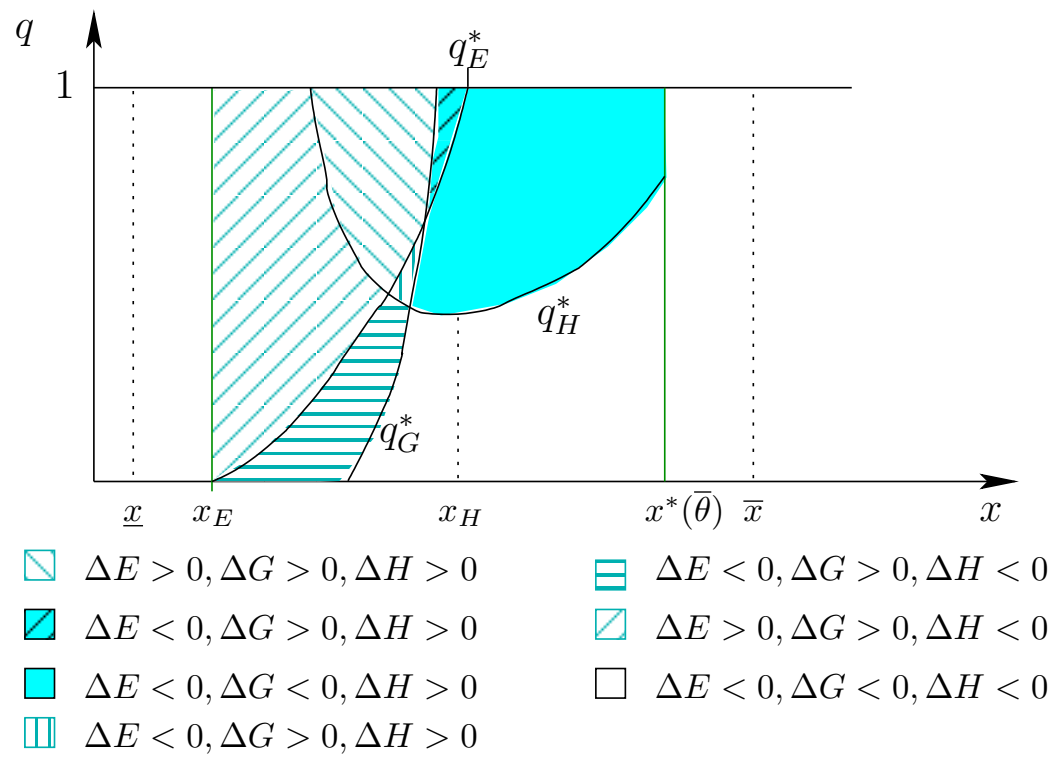

defines the share of poor students such that for any $q, q_{Y}^{*}(x) \leq q \leq 1$, the centralized system outperforms the decentralized one while for any $q, 0 \leq q \leq$ $q_{Y}^{*}(x)$ the decentralized system outperforms the centralized one. That is,

$$
\begin{array}{ll}
Y_{C}(x)>Y(q), & q_{Y}^{*}(x) \leq q \leq 1, \\
Y_{C}(x) \leq Y(q), & 0 \leq q \leq q_{Y}^{*}(x) .
\end{array}
$$

When $Y_{C}(x) \leq Y_{S}$, then the decentralized system outperforms the centralized one for any $q, 0 \leq q \leq 1$ so that $q_{Y}^{*}(x)=1, \forall x$.

Therefore, for any $x_{E} \leq x \leq x^{*}(\bar{\theta})$, the higher the share of stayers, the more likely it is that the centralized system outperforms the decentralized one. Figure 3 graphically show ${ }^{26}$ the results of Theorem 1 .

An interesting corollary of the previous analysis concerns inter-generational mobility. Whereas in the centralized setting the family of origin affects the

\footnotetext{
${ }^{26}$ Figure 3 was drawn considering that the slope of equation 14 is given by $\frac{d q}{d x}=\frac{-\frac{d Y_{C}}{d x}}{Y_{M}-Y_{S}}$. It allows the slopes of $q_{Y}^{*}(x)$ to be computed in the three cases:

- For $Y=E, \frac{d E_{C}}{d x}<0$ and $\frac{d q_{E}^{*}}{d x}>0 \forall x \in\left[x_{E}, x_{2 E}\right]$.

- For $Y=G$, assuming $G_{M}>G_{S}, \frac{d G_{C}}{d x}<0$ and $\frac{d q_{G}^{*}}{d x}>0 \forall x \in\left[x_{E}, x_{2 G}\right]$

- For $Y=H, \frac{d H_{C}}{d x}>0$ and $\frac{d q_{H}^{*}}{d x}<0 \forall x \in\left[x_{1 H}, x_{H}\right] ; \quad \frac{d H_{C}}{d x}<0$ and $\frac{d q_{H}^{*}}{d x}>0 \forall x \in$ $\left[x_{H}, x_{2 H}\right]$. In Figure 3 assume $x_{1 H}>x_{E}$ and $x_{2 H}>x^{*}(\bar{\theta})$.
} 
choice of enrollment through the reduced willingness of poorer families to finance education (an argument extensively analyzed in the economic literature and not considered in our paper), in decentralization, movers are more likely to come from richer families that can support moving costs easily, and they choose the standard that maximizes their human capital. Stayers enroll at a sub-optimal standard, and, everything else being equal, accumulate lower human capital (see Proposition 4).

Therefore, a decentralized higher-education system reduces intergenerational mobility more severely than a centralized system.

\section{Conclusions}

Higher educational systems are intended to raise the human capital of students and to certify the quality of students who graduate. These two objectives go hand in hand since, as assumed in this paper, both depend on the difficulty faced by each student to obtain the degree and on the educational standard of the academic institution.

Our theoretical model highlights the fact that in the higher educational system considered here (i.e., a system based on the free-access principle where each student is endowed with a given talent and chooses whether to enroll or not and, eventually, self-selects among the educational standards offered), the student will enroll if her/his talent is higher than a given threshold. This threshold depends on the family income ${ }^{27}$, while the optimal standard (i.e., the standard desired by a given student) depends only on the level of student talent.

Two higher-education settings are analyzed: the centralized standard, where the policy maker sets a given standard that is common to all universities, and the decentralized standard, where all desired standards are offered by universities located in different districts. In the latter case, each student can decide not to enroll, to enroll in the university located in the district of residence whose standard is random, or to enroll in the university offering his/her preferred standard by sustaining additional moving costs.

This paper highlighted some controversial concerns about the potential consequences of "broad access and success rate" toward two fundamental policy objectives: a) human capital accumulation, and b) intergenerational mobility in education. An increase in the number of enrolled and graduated students may be reached through many different policies, namely reduction of tuition fees, grants for poor students, or more generally raising public

\footnotetext{
${ }^{27}$ Appendix A offers some empirical results of the relationship between the probability of enrolling, the individual talent, and the social class to which the student belongs.
} 
public expenses for the university system in order to raise its efficiency and quality.

Nevertheless, the easiest and least expensive way to reach these goals is by reducing the standard level.

We demonstrate that a standard level reduction implies a reduction in human capital accumulation because the standard that maximizes enrollment is lower than the standard that maximizes the human capital accumulation. The standard that maximizes the number of graduates is even lower. Therefore, the objective of increasing the number of enrolled and graduated can be detrimental to human capital accumulation.

Furthermore, it emerges from the model that the standard that maximizes the enrollment rate depends negatively on family income. Rich families would prefer a lower standard than poor ones.

Roughly speaking, if a policy maker were interested in the standard desired by rich families, he/she would set a standard below the standard desired by "poor" families. As a consequence there would be a reduction in the enrollment of "poor" students.

The decentralized standard case probably mimics an economic system where university "autonomy" exists. In that case, human capital accumulation during studies is maximized only if all secondary school dropouts can choose the preferred standard and sustain mobility costs. If this is not the case ${ }^{28}$, a share of secondary school dropouts is constrained to either not enroll or to enroll at the (random) university located at home. Family income influences not only the enrollment decision, but also the human capital accumulation during studies because students who move toward the "preferred" standard, the movers, accumulate more human capital than the stayers. Therefore, apart from well-known differences in the enrollment rate among rich and poor students, another limit to intergenerational mobility in education emerges in higher-education settings based on the decentralized standard if the "poor" enrolled students are less likely to choose their preferred standard and therefore accumulate a lower level of human capital.

We also demonstrate that the centralized system achieves better performance with respect to the decentralized one in terms of both enrollment and human capital accumulation if the share of stayers in the population is higher than a given threshold. Given an objective pursued by the policy maker in a centralized system, this threshold will be close to its smallest value if the standard is close to the standard that maximizes the objective of the policy maker.

Our results suggest that:

\footnotetext{
${ }^{28}$ As empirically highlighted in the appendix A for Italy.
} 
a) "broad access" can have positive effects on economic growth. Nevertheless, if it is actually achieved by lowering the standard, this is detrimental to human capital accumulation.

b) autonomy of individual universities in the process of standard setting must be linked to policies aimed at financing mobility costs. Without this, intergenerational mobility in education and even human capital accumulation are reduced.

The paper presents some critical points that deserve further investigation. Specifically,

- In decentralization, we have assumed that all the desired standards are actually offered, without considering the optimal behavior of the individual universities. An analysis of the strategic behavior of university management in choosing the standard is an interesting area for future research.

- The wage premium for graduation has been taken as an exogenous parameter (partial equilibrium). Considering graduates' wage determination in a general equilibrium model would be another possible development of the paper.

- An exhaustive empirical analysis has not been made. Empirical development aiming to extensively analyze the motivation behind the individual decision to enroll, move, or drop out, linked with the institutional setting (university diversification in quality, fees, standards and geographical distribution) are needed. 


\section{References}

Joseph G Altonji. The Demand for and Return to Education When Education Outcomes Are Uncertain. Journal of Labor Economics, 11(1): 48-83, January 1993. URL http://ideas.repec.org/a/ucp/jlabec/ v11y1993i1p48-83.html.

Manuel Bagues, Mauro Sylos Labini, and Natalia Zinovyeva. Differential Grading Standards and University Funding: Evidence from Italy. Working Papers 2008-07, FEDEA, February 2008. URL http://ideas.repec .org/ $\mathrm{p} /$ fda/fdaddt/2008-07.html.

Julian R Betts. The Impact of Educational Standards on the Level and Distribution of Earnings. American Economic Review, 88(1): 266-75, March 1998. URL http://ideas.repec.org/a/aea/aecrev/ v88y1998i1p266-75.html.

John Bishop and Ludger Wossmann. Institutional Effects in a Simple Model of Educational Production. Education Economics, 12(1):17-38, 2004. URL https://ideas.repec.org/a/taf/edecon/v12y2004i1p17-38.html.

John H Bishop. The Effect of National Standards and CurriculumBased Exams on Achievement. American Economic Review, 87(2): 260-64, May 1997. URL http://ideas.repec.org/a/aea/aecrev/ v87y1997i2p260-64.html.

Dan A. Black and Jeffrey A. Smith. Estimating the Returns to College Quality with Multiple Proxies for Quality. Journal of Labor Economics, 24 (3):701-728, July 2006. URL http://ideas.repec.org/a/ucp/jlabec/ v24y2006i3p701-728.html.

Massimiliano Bratti, Chiara Broccolini, and Stefano Staffolani. Mass Tertiary Education, Higher Education Standard and University Reform: A Theoretical Analysis. Working Papers 277, Universita' Politecnica delle Marche (I), Dipartimento di Scienze Economiche e Sociali, February 2007. URL http://ideas.repec.org/p/anc/wpaper/277.html.

Dominic J. Brewer, Eric R. Eide, and Ronald G. Ehrenberg. Does It Pay to Attend an Elite Private College? Cross-Cohort Evidence on the Effects of College Type on Earnings. Journal of Human Resources, 34(1):104-123, 1999. URL http://ideas.repec.org/a/uwp/jhriss/ v34y1999i1p104-123.html. 
Giorgio Brunello and Lorenzo Rocco. Educational Standards in Private and Public Schools. Economic Journal, 118(533):1866-1887, November 2008. URL https://ideas.repec.org/a/ecj/econjl/ v118y2008i533p1866-1887.html.

Serena Canaan and Pierre Mouganie. Quality of higher education and earnings: Regression discontinuity evidence from the French Baccalaureate. MPRA Paper 62509, University Library of Munich, Germany, October 2014. URL http://ideas.repec.org/p/pra/mprapa/62509.html.

B. Cantillon, A. De Ridder, E. Vanhaecht, and G. Verbist. (Un)desirable effects of output funding for Flemish universities. Economics of Education Review, 30(5):1059-1072, October 2011. URL https://ideas.repec. org/a/eee/ecoedu/v30y2011i5p1059-1072.html.

Lorenzo Cappellari and Claudio Lucifora. The "Bologna Process" and college enrollment decisions. Labour Economics, 16(6):638-647, 2009. ISSN 0927-5371. doi: 10.1016/j.labeco.2009.08.009. URL http://www . sciencedirect.com/science/article/pii/S0927537109000943. European Association of Labour Economists 20th annual conference University of Amsterdam, Amsterdam, The Netherlands 18-20 September 2008.

Arnaud Chevalier and Gavan Conlon. Does It Pay to Attend a Prestigious University? IZA Discussion Papers 848, Institute for the Study of Labor (IZA), August 2003. URL http://ideas.repec.org/p/iza/izadps/ dp848.html.

Robert M Costrell. A Simple Model of Educational Standards. American Economic Review, 84(4):956-71, September 1994. URL http://ideas. repec.org/a/aea/aecrev/v84y1994i4p956-71.html.

Robert M. Costrell. Can centralized educational standards raise welfare? Journal of Public Economics, 65(3):271-293, September 1997. URL http: //ideas.repec.org/a/eee/pubeco/v65y1997i3p271-293.html.

Stefan Denzler and Stefan C. Wolter. Too Far to Go? Does Distance Determine Study Choices? IZA Discussion Papers 5712, Institute for the Study of Labor (IZA), May 2011.

Brad J. Hershbein. Worker Signals among New College Graduates: The Role of Selectivity and GPA. Upjohn Working Papers and Journal Articles 13190, W.E. Upjohn Institute for Employment Research, January 2013. URL http://ideas.repec.org/p/upj/weupjo/13-190.html. 
Oliver Himmler and Robert Schwager. Double Standards in Educational Standards - Do Schools with a Disadvantaged Student Body Grade More Leniently? German Economic Review, 14(2):166-189, 05 2013. URL https://ideas.repec.org/a/bla/germec/v14y2013i2p166-189.html.

Caroline M. Hoxby. Does Competition among Public Schools Benefit Students and Taxpayers? American Economic Review, 90(5):12091238, December 2000. URL http://ideas.repec.org/a/aea/aecrev/ v90y2000i5p1209-1238.html.

Lena Lindahl and Hakan Regnér. College Choice and Subsequent Earnings: Results Using Swedish Sibling Data. Scandinavian Journal of Economics, 107(3):437-457, 09 2005. URL http://ideas.repec.org/a/bla/scandj/ v107y2005i3p437-457.html.

Nakamuro Makiko and Inui Tomohiko. The Returns to College Quality in Japan: Does Your College Choice Affect Your Earnings? ESRI Discussion paper series 306, Economic and Social Research Institute (ESRI), November 2013. URL http://ideas.repec.org/p/esj/esridp/306.html.

Joniada Milla. University Quality and Labour Market Outcomes of Canadian Youth. Working Papers 1212, University of Guelph, Department of Economics and Finance, 2012. URL http://ideas.repec.org/p/gue/ guelph/2012-12.html.

Veruska Oppedisano. Open University Admission Policies and Drop Out Rates in Europe. Working Papers 200944, Geary Institute, University College Dublin, December 2009. URL http://ideas.repec.org/p/ucd/ wpaper/200944.html.

M. De Paola and V. Scoppa. Returns to skills, incentives to study and optimal educational standards. Journal of Economics, 92(3):229262, December 2007. URL http://ideas.repec.org/a/kap/jeczfn/ v92y2007i3p229-262.html.

Robert Schwager. Majority Vote on Educational Standards. GEMF Working Papers 2013-11, GEMF - Faculdade de Economia, Universidade de Coimbra, March 2013. URL http://ideas.repec.org/p/gmf/wpaper/ 2013-11..html.

Gonzalo Olcina Vauteren and Luisa Escriche. Education And Family Income: Can Poor Children Signal Their Talent? Working Papers. Serie AD 200620, Instituto Valenciano de Investigaciones Económicas, S.A. (Ivie), October 2006. URL http://ideas.repec.org/p/ivi/wpasad/2006-20.html. 
L. Wobmann. Why students in some countries do better: international evidence on the importance of education policy. Education Matters, 1:67-74, 2001.

Haifeng Zhang, Yang Wu, and Xianguo Yao. Does attending a key school have a quality premium? A regression discontinuity analysis. Applied Economics Letters, 20(18):1630-1635, December 2013. URL http://ideas.repec. org/a/taf/apeclt/v20y2013i18p1630-1635.html. 


\section{APPENDIX}

\section{Appendix A: A taste of empirical evidence for Italy}

The main results of the paper - the dependence of the optimal standard on the objective of the policy maker and the comparisons in the outcomes of a centralized setting versus a decentralized one - are very difficult to test empirically, mainly because of the lack of data on "standards" 29, As explained in the paper, our standard does not represent the overall quality of either the higher university system or the individual institutions (both usually available), but it represents the "difficulty" of getting the degree.

Therefore, in this appendix we offer simple multivariate statistics of the relationship between some of our key variables and individual characteristics. Specifically, we would like to know if: a) the presence of a university in the province of residence positively affects the enrollment decision; b) the moving decision is related to the social class; c) "talent" plays a minor role in explaining the drop-out decision for those students who moved.

We analyze Italy, a country where the principle of free access holds, where universities are differentiated by quality and standards (yearly scores on the quality of universities are available), and where universities are spread widely throughout the country.

We use the 2007 survey on study and work experience of secondary-school graduates (Indagine sui percorsi di studio e lavoro dei diplomati) issued by the Italian Institute of Statistics (ISTAT). The students are interviewed three years after obtaining their secondary-school diploma. In the survey, 25, 880 students who obtained their diploma in 2004 were interviewed. The dataset contains information on students' personal and household characteristics and on their educational background. Once observations with missing data on the variables of interest have been excluded, we end up with a sample of 25,512 secondary-school dropouts and 79 universities. The individual attributes we focus on are the socio-economic condition of the student's household and the student's secondary school background. As proxies of the socio-economic status of the student's family, we use the variable "social class" which is a four-class categorical variable that synthetically describes the highest job

\footnotetext{
${ }^{29}$ As already mentioned, the OECD study Assessment of Learning Outcomes in Higher Education (AHELO) is precisely aimed to provide empirical measures of "standards". At the moment, the OECD has published the "Feasibility Study". The complete analysis and reporting are expected for 2020. http://www.oecd.org/edu/skills-beyond-school/ ahelo-main-study.htm
} 
position and level of education in the family. The variable "secondary school type" indicates if the student attended a vocational school, a technical school, a liceo, a pedagogical school, or an art school.

Table 1: Descriptive statistics

\begin{tabular}{lrr|rrr}
\hline Individual characteristics & $\begin{array}{r}\text { Sample } \\
(\mathrm{N})\end{array}$ & $\begin{array}{r}\text { Enrolled } \\
(\mathrm{N})\end{array}$ & $\begin{array}{r}\text { Rates } \\
\text { Enrol. }\end{array}$ & Movers & Dropout \\
\hline Men & 11,675 & 6,123 & 0.52 & 0.50 & 0.19 \\
Women & 13,837 & 8,972 & 0.65 & 0.52 & 0.15 \\
\hline Upper class & 2,647 & 2,342 & 0.88 & 0.54 & 0.16 \\
Middle class & 4,675 & 3,054 & 0.65 & 0.53 & 0.16 \\
Working class & 9,279 & 5,959 & 0.64 & 0.50 & 0.17 \\
Working poor, underclass & 8,911 & 3,740 & 0.42 & 0.49 & 0.16 \\
\hline Vocational & 7,297 & 2,217 & 0.30 & 0.49 & 0.22 \\
Technical & 7,912 & 4,317 & 0.55 & 0.48 & 0.18 \\
Liceo & 5,473 & 5,171 & 0.94 & 0.54 & 0.13 \\
Pedagogical & 2,945 & 2,493 & 0.85 & 0.53 & 0.15 \\
Arts & 1,885 & 897 & 0.48 & 0.48 & 0.17 \\
\hline Total & 25,512 & 15,095 & 0.59 & 0.51 & 0.16 \\
\hline
\end{tabular}

- The enrollment rate is the ratio between enrolled students and secondary-school graduates.

- The moving rate is the ratio between enrolled students at a university located in a different province from the one where they finished secondary school and total enrollment. - The dropout rate is the ratio between enrolled students who changed or abandoned the university where they originally enrolled for reasons other than personal ones (having found a job, health) and total enrollment.

Source: "Indagine sui percorsi di studio e lavoro dei diplomati", 2007, ISTAT

The other key information contained in the ISTAT data is the student's province of residence during secondary schoo ${ }^{30}$ and, for enrolled students, the province of the chosen university.

As a proxy of the student's talent, we used the "final grade" obtained at the maturità exam, a nationally defined exam to be passed at the end of secondary school. The "talent" variable comes from the residuals of an estimation of the final grade on type of secondary school, province of residence and their interactions.

Table 1 presents some descriptive statistics. The first two columns show

${ }^{30} 103$ provinces, 64 of which have one or more universities. 
the composition of the sample and the composition of the enrolled. The enrollment rate, the moving rate and the drop-out rate are shown in the last three columns. Table 1 clearly shows that all rates are highly heterogeneous across individual characteristics.

We estimate the probability of enrolling, moving, and dropping out. Given that the decision to move can be observed only for the enrolled, we jointly estimate the enrollment and moving probabilities using the Heckman selection method, where enrollment is the selection equation ${ }^{31}$. The dropout equation is instead estimated by a simple probit model, so that the probability of dropping out is conditional to the enrollment decision ${ }^{32}$.

Table 2 illustrates the estimates of enrolling probability, moving probability, and dropout probability.

Table 2 allows us to confirm some crucial points in the proposed theoretical model:

- Talent significantly and positively affects enrollment and moving decisions, while it significantly and negatively affects the drop-out decision (Assumption 1 and Proposition 1(b)).

- The secondary school and social class of the family strongly affect enrollment (Proposition 1(c)) and mobility (Assumption 4). The secondary school also affects the dropout probability; this is likely due to the fact that the chosen secondary school can be another rough proxy for the individual's talent. The lower probability of drop-out observed for the working poor finds justification in the model: the marginal talent required to enroll for students in this social class is higher than the one for the upper class. In other words, enrolled students from low social classes are on average more talented (Proposition 1(c)).

- The presence of the university in the province of residence positively affects the enrollment probability and negatively affects the moving decision. This result does not hold for the upper and middle classes (results available to the authors). (Assumption 4).

- In the decision to drop out, talent is significantly less important for the movers, as shown by the interaction between talent and the dummy for movers. (Proposition 2(c)).

\footnotetext{
${ }^{31}$ Results do not change qualitatively by estimating two different probit models, one for enrollment using the entire sample and the other for moving, using only enrolled students.

${ }^{32}$ By estimating a Heckman selection model for dropping out, with enrollment as the selection factor, we obtain results that are qualitatively very similar, along with a more significant dependence of the drop-out probability on the interaction between talent and moving decision, which is our variable of interest.
} 
Table 2: Probit estimates of enrollment, moving, and dropping out.

\begin{tabular}{lrr|r}
\hline & moving & enrollment & dropping out \\
\hline Talent & $0.0084^{* * *}$ & $0.035^{* * *}$ & $-0.014^{* * *}$ \\
Women & 0.020 & $0.055^{* * *}$ & $-0.062^{* *}$ \\
\hline School-ref: vocational & $0.15^{* * *}$ & $0.64^{* * *}$ & $-0.17^{* * *}$ \\
Technical & $0.58^{* * *}$ & $2.11^{* * *}$ & $-0.43^{* * *}$ \\
"Liceo" & $0.39^{* * *}$ & $1.56^{* * *}$ & $-0.31^{* * *}$ \\
Pedagogical & $0.28^{* * *}$ & $0.38^{* * *}$ & $-0.21^{* * *}$ \\
Arts & -0.057 & $-0.43^{* * *}$ & $-0.076^{*}$ \\
\hline Social Class-ref: upper class & $-0.12^{* * *}$ & $-0.42^{* * *}$ & -0.025 \\
Middle class & $-0.22^{* * *}$ & $-0.79^{* * *}$ & $-0.14^{* * *}$ \\
Working class & $-4.06^{* * *}$ & $0.066^{* * *}$ & \\
Working poor & \multicolumn{2}{|c}{} & $-0.051^{*}$ \\
\hline Univ. in the province of residence & $0.0037^{*}$ \\
Movers & $3.01^{* * *}$ & $-0.59^{* * *}$ \\
Mover*talent & 25512 & 25512 & 10940 \\
\hline cons & $r h o$ & $0.328 * * *$ & \\
\hline N. obs & \multicolumn{2}{|c}{} \\
\hline
\end{tabular}

\section{Appendix B: Endogenous effort during studies}

We assume that effort during studies, $e$, with $0 \leq e \leq 1$, negatively affects the utility in the study period and positively affects the probability of graduation. We assume that the utility during studies is given by: $z \theta-\frac{e^{2}}{2}$, that the probability of graduation is $e \sqrt{p(x, \theta)}$, and the premium for enrollment wage is $\sqrt{2 w(x, \theta)}$. Note that the last two definitions do not change anything in the model because they simply modify Assumptions 1 and 2 .

Equation 4 becomes:

$$
V=e \sqrt{2 p(x, \theta) w(x, \theta)}-Z \theta-\frac{e^{2}}{2}
$$

Each enrolled student optimally chooses his/her effort during studies by maximizing Eq. 19, so that:

$$
e^{*}(x, \theta)=\sqrt{2 p(x, \theta) w(x, \theta)}
$$

Therefore, effort depends positively on human capital accumulation during 
studies. According to the results of the model, it always depends positively on talent and depends positively on the standard only if $x<x^{*}(\theta)$, so that the individual effort is maximized when the optimal standard is attained.

By substituting $e^{*}(x, \theta)$ in Eq. 19, we obtain

$$
V=p(x, \theta) w(x, \theta)-Z \theta,
$$

which is precisely Eq. (4) representing the premium for enrolling function. This result obviously requires a specific form of the function defining the disutility of effort and a specific relationship between the probability of graduation and effort. For these reasons, we preferred to not explicitly model effort in the paper.

\section{Appendix C: Proofs}

Proof 1 (Proof of Proposition 1).

Proof of Proposition 1 (a).

$V$ is a decreasing function of $Z$ since $E q$. (4) implies $\partial V / \partial Z=-\theta<0$.

Proof of Proposition 1 (b).

We show that for any positive value of loss of income while studying $Z$ and a positive standard $x, \underline{x} \leq x \leq \bar{x}$, there exists a talent, $\underline{\theta}(x)$, which is the smallest positive solution of the equation $V(x, \underline{\theta}(x))=0$. This talent is the lowest talent necessary to enroll at the standard $x$. We prove that $V(x, \theta) \leq 0$, for all $\theta \leq \underline{\theta}(x)$ and that $V(x, \theta, Z)>0$ for all $\theta>\underline{\theta}(x)$. In other words, it is convenient to enroll only when $\theta \geq \underline{\theta}(x)$.

The case $x=\bar{x}$ is trivial and we have $\underline{\theta}(\bar{x})=\bar{\theta}$.

Let us consider $x<x<\bar{x}$. The proof follows by the continuity of $V$ and the fact that $V(x, 0)=0, V(x, \bar{\theta})$ is positive since $x \in \underline{x}<x<\bar{x}$ and $\partial V / \partial \theta(x, 0)<0$. Let us show this last feature by deriving Eq. (4) with respect to $\theta$ and rearranging it using the elasticity $\varepsilon_{p \theta}$. We thus obtain

$$
\begin{aligned}
& \frac{\partial V}{\partial \theta}=\frac{p(x, \theta) w(x, \theta)\left[\varepsilon_{p \theta}(x, \theta)+1\right]-Z \theta}{\theta} \\
& =\frac{V(x, \theta)+p(s, \theta) w(x, \theta) \varepsilon_{p \theta}(x, \theta)}{\theta} .
\end{aligned}
$$

Eq. (20) for $\theta=0, p(x, 0)=w(x, 0)=0$ gives

$$
\frac{\partial V}{\partial \theta}(x, 0, Z)=-Z<0 .
$$

This concludes the proof since the function $V(x, \theta, Z)$ is negative to the right of $\theta=0$ and positive for $\theta=\bar{\theta}$. 
Proposition 1 (c).

Let us consider that $\underline{\theta}(x, Z)$ is defined by the equation $V(x, \underline{\theta}(x, Z), Z)=0$. We then have

$$
\frac{\partial \underline{\theta}}{\partial Z}=-\frac{\frac{\partial V}{\partial Z}}{\frac{\partial V}{\partial \theta}}=\frac{\underline{\theta}(x)}{Z \varepsilon_{p \theta}(x, \underline{\theta}(x))}
$$

since we have

$$
\frac{\partial V}{\partial \theta}(x, \underline{\theta}(x), Z)=Z \varepsilon_{p \theta}(x, \underline{\theta}(x))>0, \frac{\partial V}{\partial Z}(x, \theta, Z)=-\theta .
$$

Note that $\frac{\partial \theta}{\partial Z}$ is positive by virtue of Assumption 1 which guarantees $\varepsilon_{p \theta}(x, \underline{\theta}(x))>$ 0 .

Let us consider $\underline{\theta}(x, Z)$ as a function of $x$. Using Eq. (20) and the following,

$$
\frac{\partial V}{\partial x}=\frac{p(x, \theta) w(x, \theta)}{x}\left(\varepsilon_{p x}(x, \theta)+\beta\right)
$$

we obtain

$$
\begin{aligned}
\frac{\partial \underline{\theta}}{\partial x} & =-\frac{\frac{\partial V}{\partial x}}{\frac{\partial V}{\partial \theta}}=-\frac{\theta}{x} \frac{p(x, \theta) w(x, \theta)\left(\varepsilon_{p x}(x, \theta)+\beta\right)}{p(x, \theta) w(x, \theta)\left(\varepsilon_{p \theta}(x, \theta)+1\right)-Z \theta} \\
& =-\frac{\theta}{x} \frac{p(x, \theta) w(x, \theta)\left(\varepsilon_{p x}(x, \theta)+\beta\right)}{V(x, \theta)+p(x, \theta) w(x, \theta) \varepsilon_{p \theta}(x, \theta)} .
\end{aligned}
$$

Eq. (24) provides the slope of the isopremium for enrolling functions $V$. Using the fact that $V(x, \underline{\theta}(x), Z)=0$ in Eq. 24) we obtain:

$$
\frac{\partial \underline{\theta}}{\partial x}=-\frac{\underline{\theta}(x)}{x} \frac{\varepsilon_{p x}(x, \underline{\theta}(x))+\beta}{\varepsilon_{p \theta}(x, \underline{\theta}(x))}
$$

so that a stationary point of the function $\underline{\theta}(x), \underline{x}<x<\bar{x}$ is the value $x=x_{E}$ that satisfies

$$
\varepsilon_{p x}(x, \underline{\theta}(x))+\beta=0 .
$$

We prove that the stationary point $x=x_{E}$ of the function $\theta=\underline{\theta}(x)$ is a minimizer. In fact, by differentiating Eq. 25) with respect to $x$ and evaluating the result at $x=x_{E}$ we obtain

$$
\frac{\partial^{2} \underline{\theta}}{\partial x^{2}}\left(x_{E}\right)=-\frac{\underline{\theta}\left(x_{E}\right)}{x_{E}} \frac{1}{\varepsilon_{p \theta}\left(x_{E}, \underline{\theta}\left(x_{E}\right)\right)} \frac{\partial \varepsilon_{p x}}{\partial x}\left(x_{E}, \underline{\theta}\left(x_{E}\right)\right)>0,
$$

so that $x_{E}$ is a minimizer of $\underline{\theta}(x), x>0$. Summing up, we have shown that there exists a standard, $x_{E}$, such that the talent required to enroll is the 
lowest possible one. That is, $\underline{\theta}=\underline{\theta}\left(x_{E}\right)$ is the minimum value of the function $\theta=\underline{\theta}(x)$ and the couple $\left(x_{E}, \underline{\underline{\theta}}\right)$ is the solution of the system

$$
\left\{\begin{array}{l}
V(x, \theta, Z)=0 \\
\varepsilon_{p x}+\beta=0
\end{array}\right.
$$

The uniqueness of the minimizer follows from the fact that $\partial \underline{\theta} / \partial x$ is positive for $x>x_{E}$ since $\varepsilon_{p x}+\beta>0$ for $x>x_{E}$ and $\varepsilon_{p \theta}>0$ by virtue of Assumption 1 .

Proposition 1 (d).

Let us now prove that $x_{E}$ and $\underline{\underline{\theta}}$, as a functions of $Z$, are positive functions with constant elasticity equal to $\frac{1}{\beta}$.

For the sake of simplicity we drop the dependence of $V$ on $Z$.

Let us recall that $x_{E}$ and $\underline{\underline{\theta}}$ satisfy the linear system (28). We can rewrite the two equations of the system as follows:

$$
\begin{aligned}
& V\left(x_{E}, \underline{\underline{\theta}}\right)=0, \\
& Q\left(x_{E}, \underline{\underline{\theta}}\right)=0,
\end{aligned}
$$

where $Q$ is given by:

$$
Q\left(x_{E}, \underline{\underline{\theta}}\right):=\varepsilon_{p x}\left(x_{E}, \underline{\underline{\theta}}\right)+\beta
$$

- Differentiating Eqs. (29), (30) with respect to $Z$ we find that the derivatives of $x_{E}$ and $\underline{\underline{\theta}}$ with respect to $Z$ are the solution of the following linear system:

$$
\left[\begin{array}{cc}
V_{x}\left(x_{E}, \underline{\underline{\theta}}\right) & V_{\theta}\left(x_{E}, \underline{\underline{\theta}}\right) \\
Q_{x}\left(x_{E}, \underline{\underline{\theta}}\right) & Q_{\theta}\left(x_{E}, \underline{\underline{\theta}}\right)
\end{array}\right]\left[\begin{array}{c}
\frac{d x_{E}}{d Z} \\
\frac{d \underline{\bar{\theta}}}{d \bar{Z}}
\end{array}\right]=\left[\begin{array}{c}
-V_{Z}\left(x_{E}, \underline{\underline{\theta}}\right) \\
0
\end{array}\right] .
$$

Let us denote $D(Z)$ as the determinant of the matrix appearing in Eq (31). If $D(Z) \neq 0$ we have

$$
\left[\begin{array}{c}
\frac{d x_{E}}{d Z} \\
\frac{d \underline{\underline{\underline{\theta}}}}{d Z}
\end{array}\right]=\frac{1}{D(Z)}\left[\begin{array}{cc}
Q_{\theta}\left(x_{E}, \underline{\underline{\theta}}\right) & -V_{\theta}\left(x_{E}, \underline{\underline{\theta}}\right) \\
-Q_{x}\left(x_{E}, \underline{\underline{\theta}}\right) & V_{x}\left(x_{E}, \underline{\underline{\theta}}\right)
\end{array}\right]\left[\begin{array}{c}
-V_{Z}\left(x_{E}, \underline{\underline{\theta}}\right) \\
0
\end{array}\right],
$$

that is

$$
\begin{aligned}
& \frac{d x_{E}}{d Z}=-\frac{1}{D(Z)} Q_{\theta}\left(x_{E}, \underline{\underline{\theta}}\right) V_{Z}\left(x_{E}, \underline{\underline{\theta}}\right) \\
& \frac{d \underline{\underline{\theta}}}{d Z}=\frac{1}{D(Z)} Q_{x}\left(x_{E}, \underline{\underline{\theta}}\right) V_{Z}\left(x_{E}, \underline{\underline{\theta}}\right) .
\end{aligned}
$$


Let us now compute the functions appearing in Eqs. (33) and (34). We have

$$
\begin{aligned}
& V_{x}=p_{x} w+p w_{x} \quad V_{\theta}=p_{\theta} w+p w_{\theta}-Z \quad V_{Z}=-\theta \\
& Q_{x}=\frac{\partial}{\partial x} \epsilon_{p x} \quad Q_{\theta}=\frac{\partial}{\partial \theta} \epsilon_{p x} .
\end{aligned}
$$

Since $p$ is a homogeneous function of degree zero (specifically, $p_{\theta}=-x p_{x} / \theta$, $\left.\frac{\partial}{\partial x} \epsilon_{p x}=-\frac{\theta}{x} \frac{\partial}{\partial \theta} \epsilon_{p x}\right)$ and $w_{x}=\beta w / x, w_{\theta}=w / \theta, \epsilon_{p x}=-\beta, Z /(p w)=1 / \underline{\underline{\theta}} w e$ can rewrite the determinant $D(Z)$ as follows:

$$
\begin{aligned}
& D(Z)=\left(p_{x} w+p w_{x}\right) \frac{\partial}{\partial \theta} \epsilon_{p x}-\left(p_{\theta} w+p w_{\theta}-Z\right) \frac{\partial}{\partial x} \epsilon_{p x}= \\
& \left(p_{x} w+p w \frac{\beta}{x_{E}}\right) \frac{\partial}{\partial \theta} \epsilon_{p x}-\left(-\frac{x_{E}}{\underline{\underline{\theta}}} p_{x} w+p \frac{w}{\underline{\underline{\theta}}}-Z\right)\left(-\frac{\underline{\underline{\theta}}}{x_{E}}\right) \frac{\partial}{\partial \theta} \epsilon_{p x}= \\
& p w\left(\epsilon_{p x}+\beta\right) \frac{\partial}{\partial \theta} \epsilon_{p x}+\left(-p_{x} w+\frac{p w}{x_{E}}-Z \frac{\underline{\underline{\theta}}}{x_{E}}\right) \frac{\partial}{\partial \theta} \epsilon_{p x}= \\
& \frac{p w}{x_{E}}\left(-\epsilon_{p x}+1-1\right) \frac{\partial}{\partial \theta} \epsilon_{p x}=\beta \frac{p w}{x_{E}} \frac{\partial}{\partial \theta} \epsilon_{p x},
\end{aligned}
$$

that is

$$
D(Z)=\beta \frac{Z \underline{\underline{\theta}}}{x_{E}} \frac{\partial}{\partial \theta} \epsilon_{p x}
$$

Using $\varepsilon_{p x}\left(x^{*}(\theta), \theta\right)=p_{x}^{\prime} \frac{x^{*}(\theta)}{p}=-\beta$ we have

$$
\frac{\partial \varepsilon_{p x}}{\partial \theta}\left(x^{*}(\theta), \theta\right)=\left(p_{x \theta}^{\prime \prime} \frac{x^{*}(\theta)}{p}-p_{x}^{\prime} \frac{x^{*}(\theta)}{p^{2}} p_{\theta}^{\prime}\right)=\frac{1}{p}\left(x^{*}(\theta) p_{x \theta}^{\prime \prime}+\beta p_{\theta}^{\prime}\right)
$$

where all the derivatives in the previous equation are evaluated at $x=x^{*}(\theta)$ and the equation $\varepsilon_{p x}\left(x^{*}(\theta), \theta\right)=p_{x}^{\prime} \frac{x^{*}(\theta)}{p}=-\beta$ is used.

It is easy to see that the determinant $D(Z)$ is positive by virtue of Assumption 1 and Eq. (39). Using (38) in Eqs. (39) and (34) we obtain

$$
\frac{d x_{E}}{d Z}=\frac{x_{E}}{\frac{\partial}{\partial \theta} \epsilon_{p x} \beta Z \underline{\underline{\theta}}}\left(\frac{\partial}{\partial \theta} \varepsilon_{p x}\right) \underline{\underline{\theta}}=\frac{1}{\beta} \frac{x_{E}}{Z}
$$

and

$$
\frac{d \underline{\underline{\theta}}}{d Z}=\frac{x_{E}}{\frac{\partial}{\partial \theta} \epsilon_{p x} \beta Z \underline{\underline{\theta}}}\left(\frac{\underline{\underline{\underline{\theta}}}^{2}}{x_{E}} \frac{\partial}{\partial \theta} \varepsilon_{p x}\right)=\frac{1}{\beta} \frac{\underline{\underline{\theta}}}{Z}
$$


Eqs. (40) and (41) can be rewritten as follows:

$$
\begin{aligned}
& \epsilon_{\underline{\underline{\theta}} Z}=\frac{Z}{\underline{\underline{\theta}}} \frac{d \underline{\underline{\theta}}}{d Z}=\frac{1}{\beta} \\
& \epsilon_{x_{E} Z}=\frac{Z}{x_{E}} \frac{d x_{E}}{d Z}=\frac{1}{\beta} .
\end{aligned}
$$

This concludes the proof.

Proof 2 (Proof of Proposition 2).

Proof of Proposition 2 (a).

We look for the maximizer of $V(x, \theta, Z)$ for a given $\theta$ and $Z$. To this end, we compute a stationary point of $V$ and we show that it is a maximizer. ¿From $E q$. (23), a stationary point of $V$ for a given value of $\theta$ and $Z$ is the solution to

$$
\varepsilon_{p x}(x, \theta)+\beta=0 .
$$

The existence of a zero in Eq. (43) follows the observation that $\varepsilon_{p x}(0, \theta)=0$ and that

$$
\frac{\partial \varepsilon_{p x}}{\partial x}<0, x>0 .
$$

Let us demonstrate Eq. (44). Deriving $\varepsilon_{p x}$ with respect to $x$ we obtain

$$
\frac{\partial \varepsilon_{p x}}{\partial x}=\frac{1}{p}\left(x p_{x x}^{\prime \prime}+p_{x}^{\prime}\left(1-\varepsilon_{p x}\right)\right) .
$$

Then, since $p$ is a homogeneous function of degree zero in $(x, \theta)$, the equation $p_{x}^{\prime}=-\left(x p_{x x}^{\prime \prime}+\theta p_{x \theta}^{\prime \prime}\right)$ holds (see Eq. (c) in note 13). By substituting this equation in Eq. (45) we have

$$
\frac{\partial \varepsilon_{p x}}{\partial x}=\frac{1}{p}\left(s p_{x x}^{\prime \prime}-\left(x p_{x x}^{\prime \prime}+\theta p_{x \theta}^{\prime \prime}\right)\left(1-\varepsilon_{p x}\right)\right) \Longrightarrow \frac{\partial \varepsilon_{p x}}{\partial x}=-\frac{\theta}{p} p_{x \theta}^{\prime \prime}\left(1-\varepsilon_{p x}\right) .
$$

By virtue of Assumption 1 we have $p_{x \theta}^{\prime \prime}>0$ and $\varepsilon_{p x}<0$ so that Eq. (46) implies Eq. (44). Note that since $x^{*}$ satisfies (43) choosing $\theta=\underline{\underline{\theta}}$ we get $x^{*}(\underline{\underline{\theta}}(Z))=x_{E}$.

Let us conclude this proof showing that $x_{E}$ is a maximizer. We have:

$$
\begin{aligned}
& \frac{\partial^{2} V}{\partial x^{2}}=\frac{1}{x} \frac{\partial(p(x, \theta) w(x, \theta))}{\partial x}\left(\varepsilon_{p x}(x, \theta)+\beta\right)-\frac{p(x, \theta) w(x, \theta)}{x^{2}}\left(\varepsilon_{p x}(x, \theta)+\beta\right) \\
& \quad+\frac{p(x, \theta) w(x, \theta)}{x} \frac{\partial}{\partial x} \varepsilon_{p x}(x, \theta)
\end{aligned}
$$

so that, Eqs. (43) and (44) imply that $\frac{\partial^{2} V}{\partial x^{2}}\left(x^{*}, \theta\right)<0$. 
Proof of Proposition 2 (b).

Let us show that the optimal standard $x^{*}(\theta)$ is an increasing linear function of student talent. Due to the fact that $x^{*}(\theta)$ satisfies Eq. (43) we have

$$
\frac{d x^{*}(\theta)}{d \theta}=-\frac{\frac{\partial \varepsilon_{p x}}{\partial \theta}}{\frac{\partial \varepsilon_{p x}}{\partial x}}
$$

where $\frac{\partial \varepsilon_{p x}}{\partial x}$ is negative (see Eq. (44)) so that $\operatorname{sign}\left(\frac{\partial x^{*}}{\partial \theta}\right)=\operatorname{sign}\left(\frac{\partial \varepsilon_{p x}}{\partial \theta}\right)$ with $\frac{\partial \varepsilon_{p x}}{\partial \theta}$ at $x=x^{*}(\theta)$ given by Eq. (39). Eq. (39) can be further simplified by using the homogeneity property of $p(x, \theta)$ (see note 13, point (a) and (c)), obtaining

$$
\frac{\partial \varepsilon_{p x}}{\partial \theta}\left(x^{*}(\theta), \theta\right)=-\frac{1}{p} \frac{x}{\theta}\left((1+\beta) p_{x}^{\prime}+x p_{x x}^{\prime \prime}\right) .
$$

Therefore, from Eqs. (48), (49) and (45), after substituting $-\varepsilon_{p x}=\beta$ in the latter, we obtain:

$$
\frac{d x^{*}}{d \theta}(\theta)=\frac{\theta}{x^{*}(\theta)}>0 .
$$

Proof of Proposition 2 (c).

We have to prove that $\frac{d p}{d \theta}\left(x^{*}(\theta), \theta\right)=0$, for any $\theta$. Let us start by computing

$$
\frac{d p\left(x^{*}(\theta), \theta\right)}{d \theta}=p_{x}^{\prime} \frac{d x^{*}(\theta)}{d \theta}+p_{\theta}^{\prime}
$$

where $\frac{d x^{*}(\theta)}{d \theta}$ is given in Eq. (50). Using Eq. (a) of note 13 (i.e. $\left.p_{\theta}^{\prime}=-p_{x}^{\prime} \frac{x}{\theta}\right)$, the thesis follows:

$$
\frac{d p\left(x^{*}(\theta), \theta\right)}{d \theta},=0
$$

and this concludes the proof.

Proof 3 (Proof of Proposition 3)

We look for a stationary point of $E_{C}$. From Eq. (8) we obtain

$$
\frac{\partial E_{C}}{\partial x}(x)=-\phi(\underline{\theta}(x)) \frac{\partial}{\partial x} \underline{\theta}(x)
$$

and

$$
\frac{\partial^{2} E_{C}}{\partial x^{2}}(x)=-\phi^{\prime}(\underline{\theta}(x))\left(\frac{\partial}{\partial x} \underline{\theta}(x)\right)^{2}-\phi(\underline{\theta}(x)) \frac{\partial^{2}}{\partial x^{2}} \underline{\theta}(x),
$$

so that a stationary point is point $x_{E}$ such that

$$
\frac{\partial}{\partial x} \underline{\theta}\left(x_{E}\right)=0 .
$$


That is, $x_{E}$ is the value of the standard which is the solution to the following equation:

$$
\varepsilon_{p x}\left(x_{E}, \underline{\theta}\left(x_{E}\right)\right)=-\beta .
$$

Using Eq. (54) in Eq. (53) and with Eq. (27), we obtain that $x_{E}$ is a maximizer of $E_{C}$. By virtue of $E q$. (25) and $E q$. (8) we can conclude that $E_{C}$ is a decreasing function for $x>x_{E}$ and $\theta>\underline{\theta}(x)$, hence $x_{E}$ is the unique maximizer.

We now consider the graduation rate (8) with $Y=G$. The standard $x=x_{G}$ that maximizes the graduation rate is a stationary point of $G_{C}$. The partial derivative of $G_{C}$ with respect to $x$ is given by

$$
\frac{\partial G_{C}}{\partial x}(x)=-p(x, \underline{\theta}(x)) \phi(\underline{\theta}(x)) \frac{\partial}{\partial x} \underline{\theta}(x)+\int_{\underline{\theta}(x)}^{\bar{\theta}} p_{x}^{\prime}(x, \theta) \phi(\theta) d \theta .
$$

Computing Eq. (56) at $x=x_{E}$ and using Assumption $1\left(p_{x}^{\prime}(x, \theta)<0, \forall x, \theta\right)$ we have:

$$
\frac{\partial G_{C}}{\partial x}\left(x_{E}\right)=+\int_{\underline{\theta}\left(x_{E}\right)}^{\bar{\theta}} p_{x}^{\prime}\left(x_{E}, \theta\right) \phi(\theta) d \theta<0,
$$

Therefore, $x_{G} \leq x_{E}$ since $G_{C}$ is decreasing at $x=x_{E}$.

We now consider the human capital accumulation Eq. (8). The partial derivative of $H_{C}$ with respect to $x$ is given by

$$
\begin{aligned}
& \frac{\partial H_{C}}{\partial x}(x)=-p(x, \underline{\theta}(x)) w(x, \underline{\theta}(x)) \phi(\underline{\theta}(x)) \frac{\partial}{\partial x} \underline{\theta}(x) \\
& +\int_{\underline{\theta}(x)}^{\bar{\theta}} \frac{\partial}{\partial x}[p(x, \theta) w(x, \theta)] \phi(\theta) d \theta .
\end{aligned}
$$

We have

$$
\frac{\partial}{\partial x}(p w)(x, \theta)=p w\left(\varepsilon_{p x}+\beta\right)>0, \quad x \geq x_{E}, \theta>\underline{\theta}\left(x_{E}\right),
$$

where $x_{E}$ is the maximizer of the Enrollment rate also given in Proposition 1 .

Evaluating (58) at $x=x_{E}$ and using Eqs. (54) and (59), we obtain

$$
\frac{\partial H_{C}}{\partial x}\left(x_{E}\right)=\int_{\underline{\theta}\left(x_{E}\right)}^{\bar{\theta}} \frac{\partial(p w)}{\partial x}\left(x_{E}, \theta\right) \phi(\theta) d \theta>0 .
$$

Hence we have $x_{E}<x_{H}$.

Let us now evaluate Eq. (58) at $x=x^{*}(\bar{\theta})$. Recalling that $x^{*}(\bar{\theta})>x_{E}$, this implies $\frac{\partial}{\partial x} \underline{\theta}\left(x^{*}(\bar{\theta})\right)>0$ so we obtain

$$
-p\left(x^{*}(\bar{\theta}), \underline{\theta}\left(x^{*}(\bar{\theta})\right)\right) w\left(x^{*}(\bar{\theta}), \bar{\theta}\right) \phi\left(\underline{\theta}\left(x^{*}(\bar{\theta})\right)\right) \frac{\partial}{\partial x} \underline{\theta}\left(x^{*}(\bar{\theta})\right)<0 .
$$


Furthermore, we recall that $\underline{\theta}\left(x^{*}(\bar{\theta})\right)<\bar{\theta}$ and $\frac{\partial}{\partial x}[p(x, \theta) w(x, \theta)]<0$ when $x>x^{*}(\theta)$. Hence, bearing in mind that $x^{*}(\theta)<x^{*}(\bar{\theta})$, we have that

$$
\int_{\underline{\theta}\left(x^{*}(\bar{\theta})\right)}^{\bar{\theta}} \frac{\partial}{\partial x}\left[p\left(x^{*}(\bar{\theta}), \theta\right) w\left(x^{*}(\bar{\theta}), \theta\right)\right] \phi(\theta) d \theta<0 .
$$

Eqs. (61) and 62) imply $\frac{\partial}{\partial x} H_{C}\left(x^{*}(\bar{\theta})\right)<0$ and this implies $x_{H}<x^{*}(\bar{\theta})$. This concludes the proof.

Proof 4 (Proof of Proposition 4) When $Y=E$, the proof follows from the definition of the enrollment rate given in (8) and the fact that $\underline{\theta}(x)>\underline{\underline{\theta}}$.

When $Y=H$ the proof follows recalling that $x^{*}(\theta)$ maximizes $p(x, \theta) \overline{\bar{w}}(x, \theta)$ for any given value of $\theta$ and noting that:

$$
\begin{aligned}
& H_{C}(x)=\int_{\underline{\theta}(x)}^{\bar{\theta}} p(x, \theta) w(x, \theta) d \theta \leq \int_{\underline{\theta}(x)}^{\bar{\theta}} p\left(x^{*}(\theta), \theta\right) w\left(x^{*}(\theta), \theta\right) \leq \\
& \int_{\underline{\underline{\theta}}}^{\bar{\theta}} p\left(x^{*}(\theta), \theta\right) w\left(x^{*}(\theta), \theta\right)=H_{M} .
\end{aligned}
$$

Moreover, thanks to the previous results and the fact that $\int_{x_{E}}^{x^{*}(\bar{\theta})} g(s) d s=1$, we have

$$
Y_{S}=\int_{x_{E}}^{x^{*}(\bar{\theta})} g(s) Y_{C}(s) d s \leq \int_{x_{E}}^{x^{*}(\bar{\theta})} g(s) Y_{M} d s \leq Y_{M}, Y=E, H
$$

This concludes the proof.

Proof 5 (Proof of Proposition 5)

$Y_{S}$ is the average of objective $Y(Y=E, H, G)$ over the interval $\left[x_{E}, x^{*}(\bar{\theta})\right]$. Moreover, we have

$$
\begin{aligned}
& Y_{C}\left(x^{*}(\bar{\theta})\right) \leq Y_{C}(x), \forall, x_{E} \leq x \leq x^{*}(\bar{\theta}), \text { for } Y=E, G \\
& Y_{C}\left(x^{*}(\bar{\theta})\right)<Y_{S} \quad \text { for } Y=E, G .
\end{aligned}
$$

Eq. (67) implies $Y_{C}\left(x^{*}(\bar{\theta})\right)-Y_{S}<0$ and the definition of $\underline{x}($ i.e. $V(\underline{x}, \bar{\theta})=0$ ) implies $Y_{C}(\underline{x})-Y_{S}=-Y_{S}<0$. Therefore two consecutive solutions, $x_{1 Y}$ and $x_{2 Y}$, exist.

(a) when $Y=E$ we have that $E_{C}$ has a unique maximizer, $x_{E}$, so that $\frac{d}{d x} E_{C}<0$ in $x \in\left(x_{E}, x^{*}(\bar{\theta})\right)$. This implies that $x_{2 E}$ is the unique zero of the equation $E_{C}(x)-E_{S}=0$ in the interval $\left(x_{E}, x^{*}(\bar{\theta})\right)$ and that $x_{1 E}<x_{E}$ 
(b) when $Y=G$, the assumption that $G_{C}$ has a unique maximizer, $x_{G}$, guarantees that the two solutions to the equation $G_{C}(x)-G_{S}=0$ are unique. Thus, we have $x_{1 G}<x_{G}<x_{E}<x_{2 G}$ since $\frac{d}{d x} G_{C}<0$ in $x \in\left(x_{E}, x^{*}(\bar{\theta})\right.$ ) (see Eq. (67) and Proposition 3).

(c) when $Y=H$, we have $Y_{C}(\underline{x})-Y_{S}<0$ and $Y_{C}(\bar{x})-Y_{S}<0$ since $\underline{\theta}(\underline{x})=\underline{\theta}(\bar{x})=\bar{\theta}$. This finding, together with the assumption that $H_{C}$ has a unique maximizer, $x_{H}$, guarantees that the two solutions of the equation $H_{C}(x)-H_{S}=0$ are unique. We thus have $x_{1 H}<x_{H}<x_{2 H}$ since $\frac{d}{d x} H_{C}<0, x>x_{H}$.

Proof 6 (Proof of Theorem 1). In Eq. (16) both the numerator and denominator are positive for each $\max \left\{x_{E}, x_{1, Y}\right\} \leq x \leq \min \left\{x^{*}(\bar{x}), x_{2, Y}\right\}$. We observe that when $Y_{C}(x)>Y_{S}$ we have $0<q_{Y}^{*}(x)<1$ as well as $\Delta Y(x)>0$ for $q>q_{Y}^{*}(x)$.

In contrast, when $Y_{C}(x) \leq Y_{S}$, Eq. (14) implies $\Delta Y(x, q)<0$ for any $q$. 